\title{
Exclamatives are nonsententials: Evidence from Arabic and other languages
}

\author{
Hussein Al-Bataineh \\ Memorial University of Newfoundland \\ hhalbataineh@mun.ca
}

June 19,2020

\begin{abstract}
Previous studies overlook the fact that exclamatives (Excls) are temporally deictic to the here and now, and they are anchored by the context rather than Tense (i.e., they lack the TP layer), and that they are constructed crosslinguistically as nonclausal projections. This paper provides an overview of the literature and highlights that the clausal type of Excls is not agreed upon, the defining features (e.g., factivity, scalar implicature, and question/answer relations) are highly controversial and cross-linguistically invalid, and previous analyses seem inconsistent, complicated, and inadequate to account for the idiosyncrasies of Excls. Unlike previous studies, the paper claims that Excls as asymmetrical small clauses selected by Excl head. This analysis accounts for the peculiarities and intricacies of the three types of Arabic Excls (i.e., Wh-Excls, vocative Excls, and verbal Excls) such as (i) their inflexible word order, (ii) case alternation on the referent, (iii) the presence of spurious prepositions, and (vi) the obligatory presence of some particles and affixes although not semantically required. Since the given peculiarities are not specific to Arabic and are found in other languages and supported by cross-linguistic data, the paper claims that the nonsentential approach is empirically more defensible and conceptually simpler to account for Excls crosslinguistically.
\end{abstract}

Keywords: Exclamation, syntactic haplology, morphological templates, case assignment, word order, factivity, scalar implicature

\section{Introduction}

According to the widespread view (e.g., Ambar, 2002; Brandner, 2010; Castroviejo, 2019; Delsing, 2010; Villalba, 2008), exclamations are linguistic expressions that express the speaker's strong feelings (e.g., surprise, enthusiasm, anger, etc.) or reactions towards some state of affairs as exemplified in (1):

1) a. What an amazing house he bought!

b. How beautiful she is!

c. John came!

d. Look, he is coming!

Sentences in (1) can be differentiated as proper exclamatives (Excls) (1a,b) whose syntactic constructions are indicative of their force (i.e., the use of how and what) and exclamations (1c,d) which can be of any clause type (i.e., declaratives, interrogatives or imperatives) with falling intonation (for a detailed differentiation between Excls and exclamations, see Miró, 2008 and Zevakhina, 2013). Compared with other clause types, Excls are relatively understudied. Apart from limited studies in the seventies (e.g., Elliott, 1974; Grimshaw, 1979; Oomen, 1979), only recently, Excls have gained some interest. The consequences of being ignored and poorly investigated include 
the lack of a precise and unique definition as indicated by Moutaouakil (2005:351, cited in Zevakhina, 2013:158) and Cruschina et al. (2015:267), and as a clause type, Excls are "not as unambiguously defined as the major clause types" (Siemund, 2015:706) because they are "not prominent in typological work" (Potsdam, 2011:660), and as a result, "there seems to be no comprehensive research on exclamatives, and each author is working on his own framework" (Oda, 2008:216, cited in Zevakhina, 2013:158).

This paper examines proper Excls in Jordanian Arabic (JA) and Modern Standard Arabic (MSA) ${ }^{1}$. In these varieties, there are three types of Excls which involve $w h$-phrases (Wh-Excls), a vocative particle (Voc-Excls), or a verbal element (V-Excls), exemplified in (2a-c), respectively:
2) a. ayš
ha-l-halāwih
what this-the-beauty
'What a (stunning) beauty!'
b. yā la-jamāl-i
$a l-t a b i ̄ ' a t-i$
O PREP-beauty-GEN the-nature-GEN
MSA
JA
'How beautiful nature is!'
c. $m \bar{a} \quad$ 'a lama Zayd-a-n
PTCL know.EXCL Zayd-ACC-N
'How knowledgeable Zayd is!
MSA

These three Excl types involve several peculiarities such as (i) inflexible word order, (ii) case alternation on the referent (which has genitive and accusative case in $(2 b, c)$, respectively, although the constructions have consistent semantics), (iii) the presence of spurious prepositions (i.e., $l a$ - in $(2 b)^{2}$ ), and (vi) the obligatory presence of some constituents which are optional in clauses (i.e., $h a$ - in (2a)). The paper shows that the given idiosyncrasies (in addition to other ones to be discussed below) are not present in equivalent clauses, and they exist also in other languages such as English, Spanish, French, Russian, Mandarin Chinese, and Oceanic languages. This situation leads the paper to reject previous proposals in the literature (discussed in section 2.2) that argue that Excls are full clauses because such assumptions leave the aforementioned peculiarities unexplainable mysteries. Additionally, previous studies overlook the fact that Excls are always temporally deictic to the here and now, that is, they are tenseless expressions that lack Tense specification because they are anchored by the context of the situation rather than Tense; hence, they lack the TP layer. The paper argues that Excls are not finite clausal projections; they are just small clauses formed of the referent and the property exclaimed about and headed by a functional head that provides the illocutionary force of utterance.

To account for the essential properties of Arabic Excls and to support the argument of their status as nonsententials, this paper provides a general overview and a critical assessment of the essential characteristics of Excls in section 2 which deals with the general structures, defining

\footnotetext{
${ }^{1}$ For an overview of these varieties, see for JA (e.g., Al-Aqarbeh, 2011; Al-Shawashreh, 2016; El-Yasin, 1985), and for MSA (e.g., Alhawary, 2011; Cantarino, 1976; Ryding, 2005). The JA variety is selected because it is the mother language of the author. The discussion of the given three varieties is hoped to provide a comprehensive view of Excls in Arabic in general.

${ }^{2}$ In non-exclamative constructions, the preposition la- 'to; belonging to; for; for the purpose of' and it is used "to express purpose, direction toward (destination), possession, the indirect object or dative concept of 'to,' and the benefactive concept of 'for' or 'on behalf of'” (for examples, see Ryding, 2005:371-373).
} 
features, clausal type, and previous analyses of Excls, respectively. Section 3 introduces the different types of Arabic Excls in detail and highlights how their structures differ from the equivalent declarative and interrogative clauses. Section 4 outlines the new approach adopted in this paper and explains the syntax of Arabic Excls in depth. Section 5 provides the implications of the approach proposed and discusses similar phenomena in other languages. Section 6 summarizes the main arguments and concludes the paper.

\section{Excls cross-linguistically}

A miscellaneous number of constructions and syntactic categories are utilized to form Excls which, unlike clauses, seem to constitute a highly heterogeneous group from a syntactic standpoint. Based on data from 45 languages, Zevakhina (2013) points out that there are five syntactic strategies of Excls, briefly listed in (3a-e):

3) a. Subject-verb inversion (in Germanic languages, Estonian, Mandarin Chinese) e.g., Did he worry!

(Zevakhina, 2013:164)

b. Anaphoric adjectives and adverbs (in English, Russian, Mandarin Chinese)

e.g., It is so hot!

(Zevakhina, 2013:166)

c. Wh-phrases (in Indo-European languages, Altaic, and Uralic languages)

e.g., What a big house you have!

(Zevakhina, 2013:157)

d. Subordinate clauses (in Indo-European and North-Caucasian languages)

e.g., That he should have left without asking me!

(Zevakhina, 2013:167)

e. Noun phrases (in Germanic, Romance, Austronesian and Oceanic languages)

e.g., The amount I spent!

(Zevakhina, 2013:170)

Based on the differentiation highlighted above between Excls and exclamations, the paper argues that the first two strategies are related to exclamations, rather than proper Excls. Subject-verb inversion cannot be considered as an Excl construction because S-V inversion is one of the general properties of interrogatives, and the example given is actually an interrogative (cf. 'Did he worry?') with a falling intonation. Considering $\mathrm{S}-\mathrm{V}$ inversion a syntactic property of exclamative wrongly predicts that *How smart is Sally! is grammatical, and it is a mystery why S-V inversion does not take place despite wh-movement. Assuming that interrogatives (including yes/no questions in (3a)) and exclamatives to have the same syntactic mechanisms except for the presence/ absence of a feature that triggers T-to-C movement leads to wrong predictions; for example, we erroneously assume that exclamatives and embedded questions in English are identical, contrary to fact (see, e.g., Elliott, 1974 and Grimshaw, 1979, for details). Moreover, we cannot explain why What a fool he is! is well-formed, but its interrogative equivalent with $\mathrm{S}-\mathrm{V}$ inversion is not, *What a fool is he? Relatedly, we cannot satisfactorily clarify why constructions such as *Who John saw! and *What John saw! are ungrammatical although they are CPs with wh-movement and no S-V inversion exactly like other wh-exclamatives (cf. How smart John is!) ${ }^{3}$.

\footnotetext{
3 This argument becomes more evident in tenseless languages like Ewe (a Niger-Congo language spoken in Togo and Ghana) in which yes/ no questions and exclamatives cannot have the same construction, and they cannot be used interchangeably, as shown in (1a,b), respectively (Gladstone Deklu, p.c.):
} 
Anaphoric adjectives and adverbs cannot also be considered as an Excl strategy for several reasons. First, the distinction between anaphoric adverbs like so and degree adverbs like very that "the former can refer to the previous context, whereas the latter cannot" (Zevakhina, 2013:165) cannot qualify such adverbs to be used exclusively as genuine Excls, as the given example in (3b) can be used as a declarative clause as evidenced in its syntax and the role of prosody for determining its speech-act force. Second, as correctly highlighted by the reviewer, adverbs and adjectives cannot be labeled "anaphoric" as they cannot refer to an entity mentioned previously because they lack the Person feature responsible for anaphoricity. Third, the primary criterion for distinguishing so from very is the presence of 'scalar implicature' only in the former (based on Michaelis' (2001) arguments), and this feature is argued to be cross-linguistically invalid (see section 2.3 for details).

The remaining three strategies to construct Excls cross-linguistically, viz., wh-phrases, subordinate clauses and noun phrases, are not independent clauses. The main components of $w h$ phrases such as What a big house you have! are the referent [DP a big house you have] and the exclamative pronoun what; hence, there is no evidence or need for T node projection (more details in section 4) ${ }^{4}$. In a similar vein, subordinate clauses and noun phrases function as DPs and need a verbal predicate to form a TP, for example, the Excl in (3c) needs V and T nodes to form the sentence The amount I spent exceeds $100 \$$. This unconventional view ${ }^{5}$ finds support in (i) the debate in the literature concerning the clausal type of Excls, (ii) the relatively inconsistent analyses of their structure compared with those of clauses, (iii) the debatable defining features of Excls, and (vi) the syntax of Excls in Arabic and other languages, in the following sections, respectively.

\subsection{Sentence type}

While traditional grammars characterize Excls as a sentence type distinguishable from interrogatives, declaratives, and imperatives (Gutiérrez-Rexach, 2001: 168), recent studies disagree on the clause status of Excls whether it is a separate clause type (e.g., Elliott, 1974; Gutiérrez-Rexach, 2001; Ono, 2006; Bennis, Corver, \& Den Dikken, 1998) or just a derivation of other clause types (e.g., Rosengren, 1997; Zanuttini \& Portner, 2000; Miró, 2008; Siemund, 2015). The paper argues that this debate is caused by the fact that Excls have a unique syntax that takes some, but not all, properties one expects to find in clauses. That is, they resemble both interrogatives and declaratives but only partially due to the lack of the TP layer (the projection that differentiates between full clauses/sentences and constructions smaller than a full clause (i.e., nonsententials)). Contra previous studies, the paper claims that Excls are nonsentential constructions, and they do not have the general properties of clauses. The peculiarities of Excls can support this claim compared to clauses.

\footnotetext{
1) a. exo-a nyakpo-a house-the beautiful-Q PTCL 'Is the house beautiful?'

b. exo-a nyakpo gto house-the beautiful really.EXCL 'How beautiful the house is!'

${ }^{4}$ Based on a corpus study of 703 tokens of what-Excls and 645 tokens of how-Excls, Siemund (2015:697) finds that "English Excls typically occur in reduced form lacking an overt verbal predicate, i.e. What a wonderful journey! or How

${ }^{5}$ Cantarino (1976:202, cited in Firanescu, 2003:114) points out that Excls "could be considered independent of any syntactical construction."
} wonderful!" 
Compared with interrogative clauses, Excls have a wh-element in the initial position (e.g., 1a,b) but, unlike interrogatives, they show several peculiarities. First, they do not involve subjectverb inversion, consider the ungrammaticality of the Excl in (4a) compared to the interrogative in $(4 b)$ :

4) a. *How strong is he!

b. How strong is he?

While in interrogative root clauses, the verb moves from $\mathrm{T}$ to $\mathrm{C}$; consequently, the $\mathrm{S}-\mathrm{V}$ inversion takes place, the same syntactic mechanism is not possible in Excls simply because there is no $\mathrm{T}$ position from which the verb moves to $\mathrm{C}$ (the position capable of hosting the moved verb), and as highlighted above, assuming that interrogatives and exclamatives to have the same syntactic mechanisms except for the presence/ absence of a feature that triggers T-to-C movement leads to wrong predictions. Second, while the $w h$-phrase stays in situ in echo questions (5a), the same $w h$ phrase must move in Excls, as evidenced in the ungrammaticality of (5b):

5) a. He speaks what languages?

b. *He speaks what languages!

The obligatory movement of wh-phrase in Excls indicates that what languages does not have the same position as in clauses (i.e., interrogatives such as (5a) or declaratives, e.g., He speaks five languages.). Third, while the preposition can be pied-piped along with the DP in both declaratives and interrogatives in $(6 a, b)$, the preposition must be stranded in Excls in $(6 c)$.

6) a. In a big house they live.

b. In what house do they live?

c. *In what a house they live!

(reported by Obenauer, 1994, cited in D'Avis, 2016:161)

The ungrammaticality of (6c) indicates that, unlike the clauses which have the PP as the complement of the verb live in the TP domain, the Excl has a different structure in which the preposition and the DP cannot form one constituent. Fourth, Excls can be initiated only with what and how, but not with other wh-words like why, when, where, etc. Villalba (2008:32) highlights that "why Excls are lacking universally" ${ }^{6}$. This property can be straightforwardly accounted for by the non-clausal approach of Excls. While in matrix wh-questions, the wh-word can vary depending on the moved element within TP to spec-CP, and there are several possibilities as the $w h$-word can be an argument or an adjunct, in Excls the $w h$-elements are very restricted because the whole construction is not a full clause but a small clause consisting of the referent and the property exclaimed about (more details in section 4), that is, no possible source of further wh-phrases, except how and what which are the $w h$-versions of the AP predicate (i.e., the property exclaimed about). Furthermore, some language-specific requirements are imposed on the exclamative, but not on the interrogative construction, for example, the necessity of the Mood particle in Excls (Ono, 2006). See also Elliott (1974) for more distinctions between interrogatives and Excls.

Concerning their relevance to declaratives, although in some languages like Japanese, Excls are argued to have a declarative syntax (Yamato, 2010), Excls have syntactic and pragmatic unique properties distinguishable from declaratives. Syntactically, unlike declaratives, Excls can be elliptical (e.g., How beautiful Sally is! vs. How beautiful!), but declaratives cannot (Sally is very beautiful. vs. * Sally.) (see also Zevakhina, 2013). From a pragmatic standpoint, Excls cannot be used in situations

\footnotetext{
${ }^{6}$ As suggested by the reviewer, why may be ruled out on independent grounds, that is, it maybe lacks the necessary quantification property that may be available with other wh-words, such as how or what.
} 
in which a declarative is required. Agreeing with Miró (2008:53), Excls cannot be used "to satisfy the addressee's need of information or to defend the speaker's point of view," that is, they cannot be uttered in narrations or debates. Moreover, Excls cannot always be used as answers to questions in section. The syntactic and pragmatic properties of Excls may suggest that they are not declaratives with a marked intonation.

Based on the arguments above, Excl syntax is distinct from both interrogatives and declaratives and cannot have all properties of clauses. Therefore, analyzing Excls to be derived by raising/ merger of an element to/in spec-CP fails to account for the given peculiarities above as Excls are temporally deictic (i.e., they lack the T layer).

\subsection{Left periphery}

Although most, if not all, studies follow Bennis, Corver, \& Den Dikken's (1998) argument of the existence of [+EXCL] feature in $\mathrm{C}$ that must be lexically realized, they do not agree on the analysis of Excls, that is, they provide different proposals for the features and the phrases involved in Excls (see, e.g., Ambar, 2002; Castroviejo, 2019; Cruschina et al., 2015; Gutiérrez-Rexach, 2001, 2008; Honda, 2011; Jónsson, 2010; Ono, 2006; Yamato, 2010). To illustrate, studies disagree on the internal structure of the highest projection and its divisions (mostly argued to be discourse-related projections) at the C level. For example, Gutiérrez-Rexach (2001) argues that Spanish Excls are derived by raising/ merger of an element to/in the specifier of the $\mathrm{CP}$ which is divided into three phrases, viz., ForceP, FocusP, and TopicP, represented as follow: [Force V/C/Adv/P/Det/Wh [Focus (A/N/ [+F]) [Topic ... ]]], based on the existence of [+EXCL] feature which merges with Force and connects with Focus to generate semantic effects, especially scalar implicature. Ono (2006) and Yamato (2010) argue for different projections, namely, MoodP, FocusP, and FiniteP, for Japanese Excls to account for the order of no, da and roo particles, represented as [MoodP [FocusP [FiniteP [IP ...nante... ][Finite no ]][Focus da ]][Mood roo ]]. A different structure is proposed by Jónsson (2010) for Icelandic Excls in which the WhP and HDegP 'High Degree Phrase' are argued to be headed by Excl (cf. Cruschina et al., 2015).

Moreover, the paper claims that analyzing Excls as CPs leads to unavoidable complicated derivations to differentiate between Excls and non-Excls. Apart from oversimplified derivations that represent Excls almost exactly as interrogatives, and consequently, fail to account for the unique syntax of Excls and its peculiarities (cf. Radford, 2009:222-224, and references therein), other derivations seem to involve inevitable complications. For example, Ambar (2002) adopts a split CP approach but with more projections as follows: XP [EvaluativeP [Evaluative' [AssertiveP [Assertive' XP $_{\text {whP }}$ [Wh' [FocusP [Focus' [XP [IP... . However, even with all the claimed projections, it is not clear why, for example, a preposition must be stranded in Excls (e.g., 6c) but not in clauses (e.g., 6a,b) or why the number of $w h$-forms are very restricted in Excls relative to interrogatives crosslinguistically.

The paper claims that the inconsistency in proposals and complications of derivations are caused by the initial assumption that Excls are full clauses/ sentences. Each study claims several projections in the $\mathrm{CP}$ domain which are different from those in other studies in their number, categories, functional heads and features. Furthermore, multiple unavoidable projections are assumed to account for the syntax of Excls which is, the paper claims, simpler and more straightforward than argued in the literature. The inconsistent and complicated projections in $\mathrm{C}$ can be easily avoided assuming Excls to be not extensions of a clausal projection as they are always temporally deictic; that is, they are not tensed. The minimalist amount of structure required to analyze Excls should involve a small clause consisting of the subject (i.e., the referent) and the predicate (i.e., the property exclaimed about) headed by a functional head in $\mathrm{C}$ that codifies the speaker's evaluation and 
exclamation. Such derivation is conceptually simpler and empirically more defensible, as argued in sections (4) and (5).

\subsection{Defining features}

The assumption that Excls have a clausal projection equivalent to declaratives and interrogatives leads to an inevitable disagreement among researchers regarding the defining features of Excls simply because the basis of differentiation is faulty as Excls are not clausal, that is, what differentiates Excls from clauses is the lack the TP layer in Excls rather than pragmatic properties (bearing in mind that any clause type uttered with falling intonation can be used as an exclamation without a change in its structure). The main features mentioned by the pioneering works of Elliott (1974) and Grimshaw (1979) and discussed in depth by Zanuttini \& Portner (2000), viz., factivity, scalar implicature, and question/answer relations, are highly debatable. Factivity refers to the property that Excls presuppose the truth of their content. As a result, they can only be selected by factive predicates (the contrast between $7 \mathrm{a}, \mathrm{b}$ ) which cannot be negated (7c) since that would lead to incoherence:

7) a. He knows how very nice it is to go to the mountains.

b. *He asked how very nice it is to go to the mountains.

c. *I don't know how very tall he is.

(Zanuttini \& Portner, 2000:124-125)

The factivity feature seems controversial cross-linguistically. Yamato (2010:55) points out that "Japanese Excls may not be embedded under factive predicates." Gutiérrez-Rexach (2001:183) indicates that in Spanish, "the factivity property of Excls is lost in [C-Excls] constructions." Miró (2006:16) states that " $w h$-Excls in Catalan [...] are not easily introduced by factive verbs." According to Abels (2010:146) "there are predicates that are classified in present terminology as antifactive by Kiparsky \& Kiparsky [1970] and that do appear with embedded what-a Excls and how-very Excls." These studies show that Excls are not inherently factive, and the whole argument may fail to make a plausible generalisation.

The second property is scalar implicature. The presupposed proposition conveyed by Excls is at a high point in a scale of contextually determined propositions, for example, how beautiful Sally $i s$ ! indicates that the degree of Sally's beauty is placed on the top of a scale of different degrees of beauty according to the speaker's expectations. The argument of scalar implicature involves two widespread notions in the literature, namely, gradability and emotional affectedness. Gradability indicates that adjectives used in Excls must be gradable, adjectives like dead, married, previous cannot be exclaimed about (e.g., *How dead he was!). Although this feature seems attractive and nonnegotiable at first sight, it still has some shortcomings. Gutiérrez-Rexach (2008:121, citing Miró, 2006:118-119) points out adjectives like dry, empty or full can be used in Excls, such as How empty the cinema was!, although they denote a closed scale that cannot be widened beyond a specific point (i.e., they are 'absolute' (context-invariant) adjectives which involve a maximum or a conventional endpoint, as opposed to 'relative' adjective like tall which have an open scale (see, e.g., Schumacher, 2019), and their "high/extreme degree meaning hardly fits in with the standard Gricean typology of implicated meanings" (Villalba, 2008:15, see also Rosengren, 1997:179, for similar views). The second related notion is emotional affectedness, which denotes that emotions such as surprise and amazement are caused by situations that go beyond the speaker's expectations. The surprise/ amazement effect cannot account for some contexts like (8):

8) What a delicious dinner you have made!

(Badan \& Cheng, 2015:401) 
In this context, the speaker does not imply that s/he is surprised by the taste which s/he does not expect to be delicious. Furthermore, in Mandarin Chinese, surprise cannot be considered as an essential property of Excls even in constructions like 'How tall he is!' (ibid). In support of this view, Cruschina et al., (2015:12), agreeing with Nouwen \& Chernilovskaya (2013), argue that Excls are not always scalar. Brandner (2010:99) points out that the notions 'extreme degree' and 'emotional affectedness' are hard to define in any precise way and cannot be distinguishing features since they exist in declaratives and interrogatives as well. Agreeing with the previous arguments, the paper claims that emotional affectedness cannot be a defining feature of Excls simply because surprise or amazement are associated with interjections (e.g., Wow, Oh my God, Jesus, etc.,) rather than Excls, and the co-occurrence of interjections with Excls to yield this effect is supportive evidence.

The third property is related to question/answer relations. Excls are said to resemble interrogatives since they have a $w h$-word in an initial position, but the former is distinguished from the latter in its inability to be answered or to be used as answers (compared to declaratives). The use of $w$ h-elements cannot be considered as a defining feature of Excls because the syntactic strategies to form Excls vary across languages, and wh-Excls are different from clause types syntactically, semantically, and pragmatically. Moreover, the limited ability of Excls to be used as answers is not always true, as the following pair shows:

9) A: Why don't we go to Cala S'Alguer? B: What a wonderful idea!

(Miró, 2008:50)

Apart from the aforementioned controversial features, the paper argues that there are two defining features of Excls which are related to the nature of Excls as nonsententials. The first is 'evaluation,' that is, "the speaker has an attitude towards the degree expressed and judges it in some way or other. The hearer can agree or disagree with this evaluation" (Brandner, 2010:101). The plausibility of this feature to characterize Excls stems from the claim that all Excls 'always' involve the evaluational attitude component that requires only one type of response from the addressee (i.e., (dis)agreement). Thus, the paper argues that Excls are used by the speaker to express his/her evaluation of a particular situation; more precisely, all exclamative constructions involve the feature [EVAL] which codifies the speaker's appreciation or deprecation of a particular entity, situation or event. This feature goes hand in hand with the agreed upon [EXCL] feature which provides the illocutionary force of the utterance.

The second property is related to referentiality, in Zevakhina's (2013:163) words, "a referent, which might be an object or a situation, should be accessible in discourse" and "identifiable" (Michaelis, 2001:1041). To illustrate, let us consider (10a-c):

10) a. Someone/ a man knocked on your door yesterday.

b. Did anyone call me today?

c. How generous *someone/*a man/ *anyone is!

Whereas declarative and interrogative constructions allow nonidentifiable referents in (10a,b), Excls allow only identifiable referents, hence, the ill-formedness of (10c) (a man has non-generic meaning). The fact that the referent must be identifiable is the direct result of Excls as tenseless syntactic constructions, more specifically, as small clause nonsententials or as root small clauses that have "no Tense node [and must be] situated/anchored in Time by the context of the utterance" (Progovac, 2006:44). Since the context is the only means to provide Time for Excls, the referent must be "one for which a shared representation already exists in the speaker's mind and the hearer's mind at the time of utterance" (Lambrecht, 1996:77-78). The analysis of Excls as root small clauses also explains why the identifiability requirement is not imposed in complement small clauses (e.g., I don't consider 
[anyone smart].) whose time depends on the temporal content in $\mathrm{T}$ in the main clause, rather than the utterance time.

This subsection concludes with the claim that the controversial features (i.e., factivity, scalar implicature, and question/answer relations) cannot be the defining properties of Excls, and the more plausible features are related to evaluation and referentiality. These two features are essential to account for the syntax of Excls since they are associated with the main components of Excls as nonTP constructions, namely, the small clause which involves the subject (i.e., the identifiable referent) and the property ascribed to it (i.e., the exclamative expression) which connects with the [EVAL] and [EXCL] features. This argument, as well as the preceding ones concerning the syntactic strategies, sentence type, and analyses of Excls, pave the way to the non-clausal approach of Arabic Excls.

\section{Excls in Arabic}

Similar to English in (1a-c), Arabic exclamations are different from Excls based on syntactic formations and pragmatic function; exclamations can be of any clause type uttered with falling intonation, whereas Excls have specific syntactic formulas different from clauses and used exclusively for expressivity and evaluation. Exclamations, called in Arabic siyag atta 'ajub assamā 'yya 'acoustic exclamation formats,' depend on inference, rather than structure, for their interpretation (for a comprehensive view, see Alqurašī \& Almusawī, 2010), as in (11a,b) :

11) a. kayfa fa'al-ta hāda (wa 'anta 'aḳ-i) how did-you this and you brother-my 'How did you do this (yet you are my brother)?!'
b. (subḥ̄na
Allah) bayt-u-ka
jamīl-u-n
glorified
Allah house-NOM-your
beautiful-NOM-N

'God is glorified; your house is beautiful!'

$(11 \mathrm{a}, \mathrm{b})$ follow the syntax of interrogatives and declaratives, respectively, and their interpretation cannot be restricted to exclamations out of context. In contrast, Excls do not have the same syntax of clauses and are interpreted as evaluative without the aid of special expressions like subhāna Allah in (11b), that is, their syntax is indicative of their force. Similar to other languages (e.g., see, e.g., Elliott, 1974: 244-245), Jordanian Arabic (JA) utilizes wh-elements to form Excls, as exemplified in (12a,b):
12) a. $\check{s} \bar{u}$ dāhyeh
how cunning
'How cunning (you are)!'
b. ayš ha-l-halāwih
what this-the-beauty
'What a (stunning) beauty!'

\footnotetext{
${ }^{7}$ I use the following abbreviations: ACC: accusative; DUAL: dual; EXCL: exclamative; FEM: feminine; GEN: genitive; MASC: masculine; N: nunation (Arabic indefinite article); NOM: nominative; NW: nūn alwiqāya 'preventive n'; PL: plural; PREP: preposition; PTCL: particle; SBJ: subject; SG: singular. In the transliteration, the dot under the letter indicates that the sound is emphatic and pharyngealized; [t], [ḍ], and [s] are the emphatic counterparts of [t], [d], and [s], respectively (for an overview, see, Al-Bataineh, 2019).
} 
Only šu 'how' and ayš 'what' can be used in Excls, other wh-forms (e.g., kayf 'how,'8 lawayš 'why,' mata 'when,' min 'who,' etc.) cannot. Wh-Excls involve several peculiarities including, for example, inflexible word order, (ii) the ungrammaticality of including a finite verbal phrase, and (iii) the obligatory presence of the demonstrative-like $h a$ - which is optional in clauses. These idiosyncrasies are not present in clauses.

Additionally, in Modern Standard Arabic (MSA) and JA, Excls utilize another two syntactic strategies. The first strategy which is associated with vocative Excls (Voc-Excls) changes the vocative phrase (VocP) from being used "for calling out and attracting or maintaining the addressee's attention" (Daniel \& Spencer, 2009:626) to be utilized for expressivity and evaluation of the referent. This change is reflected in the structure of VocPs, exemplified in (13a) compared with Voc-ExclPs in $(13 b)$ :

$$
\begin{aligned}
& \text { 13) a. } y \bar{a} \quad \text { rajul-a-n, ('ag்liq al-bāab-a) } \\
& \mathrm{O} \text { man-ACC-N }{ }^{9} \text { close the-door-ACC } \\
& \text { 'Man, close the door.' } \\
& \text { b. } y \bar{a} \quad \text { la-jamāl-i al-tabì 'at- } i \\
& \mathrm{O} \text { PREP-beauty-GEN the-nature-GEN } \\
& \text { 'How captivating the beauty of nature is!' }
\end{aligned}
$$

(Al-Bataineh, 2020:5)

Although the vocative particle yā heads both constructions, Voc-Excls are distinct from VocPs in several ways. First, unlike VocPs which allow an indefinite vocative such as rajul 'a man' in (13a), the entity exclaimed about must be identifiable and accessible in the discourse due to the referentiality requirement; the word jamāl 'beauty' in (13b) is definite by annexation to altabi 'ati 'the nature.' Second, the DP after the vocative particle is assigned accusative or nominative-like case ${ }^{10}$, but in Voc-ExclPs, it is marked genitive or accusative. Third, from a semantic standpoint, VocPs and VocExclPs are differentiated based on the presence/ absence of the semantic features [ANIMACY], [EVALUATIVE], and [DEGREE]. While VocPs obligatory have [ANIMACY] feature because they are associated with the addressee (cf. * y $\bar{a}$ qalamu 'O pencil', unless the vocative is interpreted metaphorically, i.e., in personification contexts), Voc-ExclPs optionally have the feature simply because both animate and inanimate objects can be exclaimed about. [EVALUATIVE] and [DEGREE] features are obligatorily absent in VocPs but must be present in Voc-ExclPs ${ }^{11}$ explicitly as in (13b)

\footnotetext{
${ }^{8}$ In contrast with Excl wh-word $s ̌ \bar{u}$ 'how', the interrogative kayf 'how' can be followed by a TP involving an overt verb that can be of any tense. As correctly highlighted by Cantarino (1976:203), "supplying a verb would efface the exclamatory quality and thus the actual character of the phrase". For that reason, $\check{s} \bar{u}$ and kayf cannot be used interchangeably.

${ }^{9}$ I consider nunation - $n$ as a marker of indefiniteness, that is, it is a D equivalent to the definite article $a l$ - for two reasons. (i) The definite article $a l$ - and nunation $-n$ are in complementary distribution (*al-walad-u-n 'the a boy'); and (ii) both $a l$ and $-n$ cannot occur in annexation (i.e., attachment to a pronoun) *al-walad-u- $k / * w a l a d-u-n-k$, or in the construct state like *al-șadiiq-a amrin / * șadiiq-a-n amrin (Al-Ansari, 1991:740, cited in Al-Bataineh, 2020:14). The abbreviation N is used for the indefinite article $-n$ in this paper. See Al-Bataineh and Branigan (2020) for a detailed analysis of the different realizations of Ds in complex structures including, e.g., construct states, compound nominals, duals, and sound plurals.

10 The nominative-like case (called in traditional grammars mabnī 'ala aḍdam) is different from the regular nominative because the former is a default case assigned only in imperfect checking domains (i.e., when the DP has a null D). See Al-Bataineh (2020) for more details.

${ }^{11}$ It is possible to have a VocP involving a DP modified by an adjective having the [EVALUATIVE] feature, e.g., My sweet/silly son, why do you behave that way?. The distinction between the VocP My sweet/silly son and a Voc-Excl such as How silly you are! is that whereas in VocPs the adjective describes a permanent attribute (i.e., denoting an autonomous,
} 
or implicitly as in (14) which exemplifies the necessity of an evaluative element, in this case, 'udübat 'purity', that can be omitted only if inferable from the context:
14) $y \bar{a}$
$l-($ 'udübat-i)
al- $m \bar{a}{ }^{\prime}-i$
$\mathrm{O}$ the-(purity-GEN)
the-water-GEN
'How pure the water is!'

Fourth, while VocPs can be initiated by eight particles in CA or three in MSA, Voc-ExclPs are headed only by $y \bar{a}$ (for further details on MSA VocPs, see Al-Bataineh, 2020; and for Gulf Arabic Voc-ExclPs Alkuwaihes, 2017). Based on the aforementioned differences, Voc-ExclPs have a unique structure that requires [REFERENTIALITY], [EVALUATIVE], [INANIMACY] and [DEGREE] in order for the expressivity to take place, that is, the absence of one or more these features leads to non-exclamative construction; VocPs or exclamations as in (10a-c) from JA:
15) a. $y \bar{a} \quad$ salām
O peace
'O goodness!'
$\begin{array}{lcc}\text { b. } y \bar{a} & \text { 'ayn- } \bar{l} & \text { 'al }-k \\ \mathrm{O} & \text { eye-my } & \text { on-you }\end{array}$

'That's absolutely true!' 12

c. $y \bar{a} \quad k s \bar{a} r a$

$\mathrm{O}$ loss

'What a loss!'

The second strategy associated with verbal Excls (V-Excls) demands the use of one of two types of verbal constituents, viz., evaluative verbs or verbal morphological templates. Evaluative verbs include $n i$ ' $m a$ 'how excellent,' $b i$ 'sal sa 'a 'how inferior,' $h a b b a(\underline{d} \bar{a})$ 'how appreciative,' and $l a$ habba $(\underline{d} \bar{a})$ 'how depreciative.' Unlike verbs used in TPs, such as 'wake up' in (16a), these evaluative verbs must be sentence initially, hence, the ungrammaticality of (16b), and only in the past tense, notice that the present tense $y u$-ḥabbid $u$ cannot be used in (16c) (in addition to other peculiarities to be explained in section 4.3.1):
16) a. Zayd-u-n ya-stīqidu mubakkir-a-n
Zayd-NOM-N 3SG.PRES-wake up early-ACC-N
'Zayd wakes up early.'

b. *Zayd-u-n habbada

Zayd-NOM-N liked.this.EXCL

'How appreciative Zayd is!'

$\begin{array}{lll}\text { c. } h a b b a \underline{d} \bar{a} / & * y u-h a b b i \underline{d} u & \text { Zayd-u-n } \\ \text { liked.this.EXCL } & \text { 3SG.PRES-like.this.EXCL } & \text { Zayd-NOM-N } \\ \text { 'How appreciative Zayd is!' } & \end{array}$

'How appreciative Zayd is!'

acontextual evaluations), in Voc-Excls the adjectives describe a temporary attribute limited to the present time of the speech situation. That is, the [EVALUATIVE] feature in Voc-ExclPs is a context-bound.

${ }^{12}$ This expression is also used ironically as a criticism. 
In addition to evaluative verbs, V-ExclPs utilize three morphological templates, viz., fa' $u l a$, 'af'il bi-, $m \bar{a}$ 'af'ala. The exclamative expression (mostly an adjective) changes its morphological form in accordance with these strict templates that act as frames or molds that shape its word structure. In (17a-c) below, 'âlim 'knowledgeable' does not retain its morphological form in templatic VExclPs, instead it is given a shape (in bold) that conforms to the templates fa 'ula, 'af'il bi-, and $m \bar{a}$ 'af'ala ${ }^{13}$, respectively:

\section{7) a. 'aluma Zayd-u-n \\ know.EXCL Zayd-NOM-N \\ 'How knowledgeable Zayd is!' \\ b. 'a'lim bi-Zayd-i-n \\ know.EXCL PREP-Zayd-GEN-N \\ 'How knowledgeable Zayd is!' \\ c. $\boldsymbol{m} \overline{\boldsymbol{a}} \quad$ 'a lama Zayd-a-n \\ PTCL know.EXCL Zayd-ACC-N \\ 'How knowledgeable Zayd is!'}

Although these templates are semantically equivalent (i.e., they denote the same property exclaimed about) and followed by the same referent, they show several peculiarities such as (i) the referent has three cases (i.e., nominative, genitive, and accusative case in (17a-c), respectively) although the semantics seems consistent, (ii) inflexible word order, (iii) the presence of the spurious preposition $b i$ - in (17b), and (iv) the obligatory presence of the meaningless particle $m \bar{a}$ in $(17 \mathrm{c})^{14}$. These properties are not possible in full clauses. Additionally, in contrast with equivalent verbal forms utilized at the TP level, these templatic forms are constructed according to several conditions that require the exclamative expression to be originally derived from a verb that is triliteral, complete 'non-auxiliary', affirmative, gradable, etc., (for details and illustrative examples, see, Aqeel, 1980:154).

To sum up, this section differentiates between Arabic exclamations and Excls based on syntactic formations and pragmatic functions, and it briefly explains the various syntactic strategies utilized to form ExclPs which include (i) the $w h$-forms in Wh-ExclPs, (ii) the vocative particle in Voc-ExclPs, and (iii) evaluative verbs and morphological templates in V-ExclPs. The next section provides a more in-depth analysis of the syntax of Arabic ExclPs.

\section{The syntax of Arabic ExclPs}

A satisfactory, plausible analysis of Arabic ExclPs needs to account for several peculiarities and intricacies associated with the different constructions mentioned above. The paper claims that analyzing Excls to be full clauses/ sentences (criticized in section (2) above) fails to account for these

\footnotetext{
${ }^{13}$ The first template is archaic and used only in Classical Arabic, but the other two are still used in MSA and JA; $m \bar{a}$ 'af'ala is more common than 'af'il bi-which restricted only to a handful of fossilized expressions (e.g., JA 'an 'im wa 'akrim (bikum) 'How excellent and generous you are!' (see also Alhawary, 2011:322) and ('akrim) bi-lmhalli as a response to greetings such as 'ahlan wa sahlan 'welcome' (for more interjectional phrases, see Cantarino, 1976:206).

14 Apart from exclamative constructions, the preposition $b i$ - "has a wide range of uses including spatiotemporal, instrumental, and manner adverbial" and can be translated as 'at, with, in, by; by means of' depending on context (see, e.g., Ryding, 2005:367-370). The particle $m \bar{a}$ can be used as a conditional, interrogative, or negative particle as well as a relative pronoun among other uses (see, e.g., Mohammed, 2018).
} 
peculiarities and leaves them as unexplainable mysteries. A more plausible approach which analyzes Excls as nonsententials is based on the following assumptions:

1- All ExclPs, regardless of their type, start the derivation as a small clause (SC) consisting of the subject (the referent) and a predicate (the property exclaimed about, mostly an adjectival element) and lacking tense inflection. The SC is a projection of a functional head as argued by several researchers (e.g., Adger \& Ramchand, 2003; J. Bailyn \& Rubin, 1991; Bowers, 1993; Dikken, 2006; Hornstein \& Lightfoot, 1987; Svenonius, 1994, cited in Citko, 2011:751), as in (18):

18)

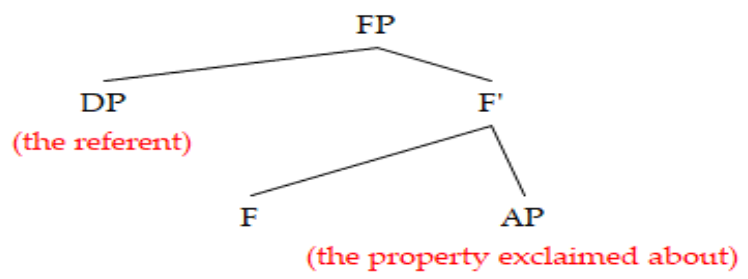

The relationship between the two constituents is predicative; the DP (i.e., the referent) is ascribed a particular property by the AP (i.e., the predicate). This assumption is based on a plethora of studies which indicate that "small clauses are both empirically motivated and theoretically sound" (Citko, 2011:751) as they are prevalent in child language (e.g., Girl hungry), and some survive into adulthood, as exemplified in (19):

19) a. Car dead./ Battery dead.

b. This a bargain?!

c. John tall?!

(Progovac, 2006)

In addition to those used as assertions in (19a) or rhetorical questions in (19b,c), Some SCs are utilized only as Excls such as those in $(20 \mathrm{a}-\mathrm{c})$ :

20) a. Oh, you fool!

b. You idiot!

c. You nincompoop/dumbass/screwball!

(Potts \& Roeper, 2006:183)

These expressive SCs may indicate how ExclPs are initially formed, especially when we consider that such expressions exist cross-linguistically, and they are not restricted to second-person pronouns (see, e.g., Corver, 2008).

2- The predication relationship between the referent and the exclamative expression is asymmetrical as they are mediated by a functional head and also nondirectional in the sense that either the subject or the predicate occupies the specifier position of the functional head, labeled as Relator $a$ la den Dikken (2006), as in (21a,b):

21) a.

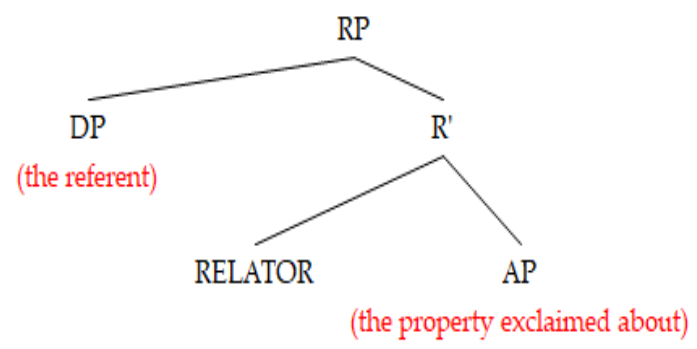

b.

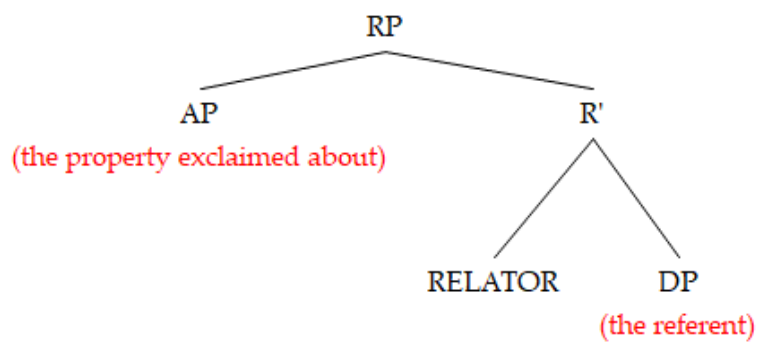


Considering that the initial position of AP in Excls, I claim that the structure in $(21 \mathrm{~b})$ is the canonical predication structure of ExclPs whereas the one in (21a) is also well-formed and allowed in constructions where the Relator follows the DP (e.g., How smart he is!). That is, the choice between either structure is both language-specific and construction-specific. The Relator is "a placeholder for any functional head in the structure that mediates a predication relation between two terms [which can be null or lexicalized as a copula, a preposition or an affix], [and since] Relator is not a designated category; the RP structure represents a syntactic configuration rather than a claim about the lexicon" (den Dikken, 2006:15-16).

3- The formed RP consists of the referent which must be accessible and identifiable in the discourse and the AP which carries the interpretable valued features [EVALUATIVE] as it embodies the speaker's evaluations (i.e., appreciation or deprecation) and [EXCLAMATIVE] as it denotes a property exclaimed about, rather than a regular adjectival modification. The RP is headed by Excl head which has uninterpretable unvalued [EVAL] and [EXCL] (i.e., not determined in advance, and they need to be valued by Agree) ${ }^{15}$ and the [EPP] feature which requires it to be extended into an ExclP (assuming that Excl head is "too weak to serve as a label" (Chomsky, 2015:9)) and it needs a specifier with agreeing features in order to be labelled). This requirement can be satisfied by either internal merge (i.e., by moving the exclamative expression) or by external merge, depending on the type of ExclP, as in (22a,b):

22) a.

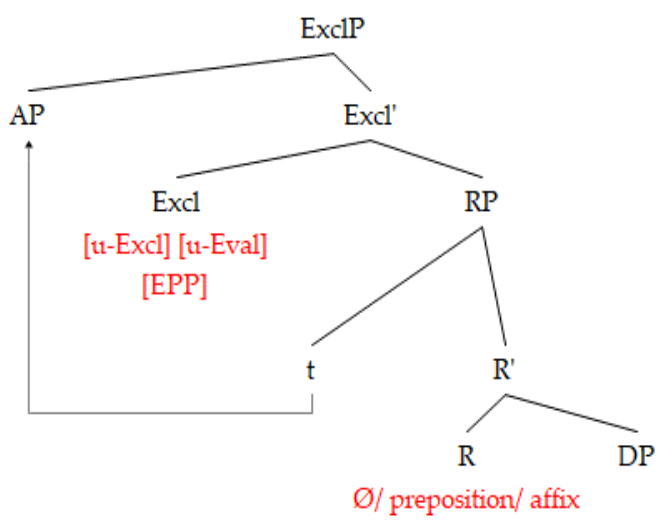

b.

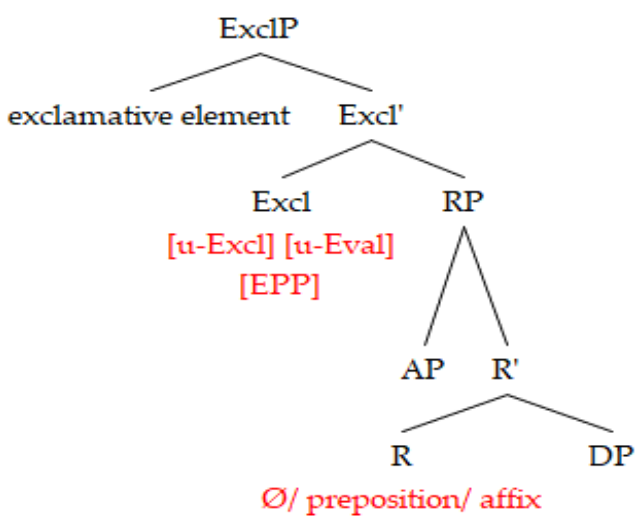

The derivation shows that Agree operation takes place between the probe Excl with its uninterpretable unvalued features and the goal AP with matching interpretable valued features. That is, Agree takes place between the AP (which is the goal since it is the lexical item semantically specified for agreement) and the probe Excl (which is not semantically specified). The uninterpretable features on Excl enter an Agree relation with the interpretable features on AP, and both features merge during syntactic computation (in Pesetsky \& Torrego's (2007:267) words, "the output is a single feature F shared by two locations. [...] Agreement results in feature sharing"), see also the analysis of whmovement in Pesetsky \& Torrego (2001) which is triggered by "an uninterpretable wh-feature on C").

This representation explains the reason why Excls are always used for evaluation (i.e., appreciation or deprecation). Notice that the $\mathrm{R}$ can be null or realized as a meaningless prepositional element or an affix in Arabic, and the external merge can be filled by a wh-element $\check{s} \bar{u} /$ ay $\check{s}$, vocative particle $y \bar{a}$ or an exclamative particle $m \bar{a}$, as explained in the following subsections. The given

\footnotetext{
${ }^{15}$ The argument that the features [EVAL] and [EXCL] are bundled in the Excl head in Arabic Excls does not impose the same mechanism to exist in all languages as these features can be either bundled or decomposed into two separate heads (i.e., Excl and Eval) both across languages and language internally.
} 
assumptions lead the paper to claim that exclamative constructions are subject to the following condition:

\section{Exclamative Condition}

A syntactic object is interpreted as an exclamative if and only if (i) it is a phrasal projection smaller than a sentence (as it lacks Tense, i.e., it is always temporally deictic to the here and now) and (ii) it is an ExclP with an exclamative specifier (i.e., a specifier containing an exclamative element).

As correctly highlighted by a reviewer, the idea of leaving out some layers (e.g., VP and TP) and having projections from the C-field (i.e., ExclP) directly above the predicate is not revolutionary in and of itself. For example, Basilico (2003) projects Topic Phrase (TopP) directly above SC to account for passivization and narrow scope phenomena. O'Neill (2015) argues that not only in tenseless languages but also in tensed languages like English, finite clauses can lack the projection of T in copula amalgam sentences. Borik \& Espinal (2019:306) argue that "in all languages, including Russian, there can be nominal arguments of different 'sizes', that is, involving a different 'amount' of functional structure on top of the minimal NP projection". Moreover, leaving out the TP layer does not affect the temporal interpretation of exclamatives because time computation does not always associate with T head. In tenseless languages such as Yucatec Maya (Bohnemeyer, 2002, 2009) and Kalaallisut (Bittner, 2005, 2008), temporal interpretation is accounted for without the need to project $\mathrm{T}$ node, that is, temporal information can be conveyed by utilizing aspect and context (discourse anaphora). Following the same logic, I claim that there is no linguistic need to project TP due to the fact that exclamatives are always temporally deictic/anaphoric to the speech time, i.e., now, the discourse-initial default (i.e., they are current at the topic/reference time).

The presence of an auxiliary in a sentence like How strong he has already been! does not constitute a counterevidence of the given assumptions simply because the auxiliary has does not originate in T but in Asp, that is, it is an aspectual marker that projects above RP (den Dikken, 2006). The possibility of having an AspP does not necessitate the presence of a TP as evidenced in the syntax of tenseless languages, for example, "the Chinese phrase structure has AspP above VP but there is no TP above AspP. This is true not only for simple sentences but for embedded clauses" (Lin, 2006:3). I claim that exclamatives have a neutral/default viewpoint aspect (i.e., they are interpreted imperfectively by default), and this aspect can be changed by the modification of a temporal adverbial and/or aspectual marker to reach non-default (perfective) interpretation (see, Bohnemeyer \& Swift, 2004, for more details). Agreeing with Lin (2010:308) that "a T node is not universally present in every language. Nor is it required in every successful theory of temporal interpretation", I claim that time computation and temporal interpretation do not necessarily rely on the existence of a syntactic T node, a remark that applies to tenseless languages mentioned above as well as Slavic languages and some African and some Arabic languages (Dragacevic, 2002) and some constructions in tensed languages (see, e.g., O’Neill, 2015).

\subsection{Wh-Excls in JA}

Wh-Excls demonstrate two intricacies compared with their declarative equivalents, viz., the obligatory presence of the demonstrative-like $h a$ - which is a demonstrative in declaratives and the inflexible word order. Consider in $(23 \mathrm{a}, \mathrm{b})$ that declaratives have flexible word order and ha- 'this' is optional, and in $(24 \mathrm{a}, \mathrm{b})$ only $\check{s} \bar{u}$ 'how' allows AP $h a$-DP, but ayš does not. Notice also that both whwords cannot allow ha-DP AP order, as shown in (25). 
23) a. $z \bar{a} k \bar{l} \quad$ (ha)-l-'akil delicious (this)-the-food 'The food is delicious.'

b. (ha)-l-'akil zākī (this)-the-food delicious 'The food is delicious.'

24) a. $\check{s} \bar{u} \quad z \bar{a} k \bar{l} \quad$ (*(ha)-l-'akil) how delicious (*(this)-the-food) 'How delicious (the food is)!'

b. *ayš zākī *(ha)-l-'akil what delicious *(this)-the-food 'How delicious (the food is)!'

\section{5) $\check{s} \bar{u} / \quad$ ayš $\quad *(h a)-l-' a k i l \quad\left(*_{z} a \bar{a} k \bar{l}\right)$ \\ what/ what *(this)-the-food (*delicious)}

'What a (delicious) food it is!'

The flexibility of word order stems from the assumption that declaratives and ExclPs may start as RPs, but they are headed by different functional heads. While RPs in declaratives project further into TP and then to CP, RPs in ExclPs are headed by Excl that requires an exclamative element to be in its specifier position either by external merge or internal merge as in $(26 a, b)$, respectively. The two derivations reflect that the AP either can stay in situ if the [EPP] feature is satisfied by external merge of an exclamative pronoun or can move if the exclamative element merges internally with the AP to form DegP 'how delicious' (the constituency of wh-AP will be discussed in section 5):

26) a.

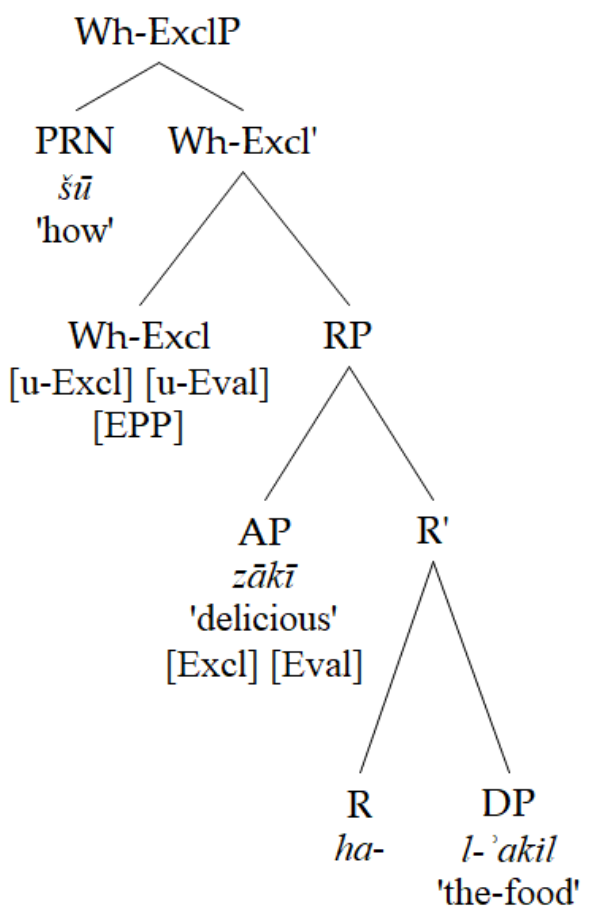

b.

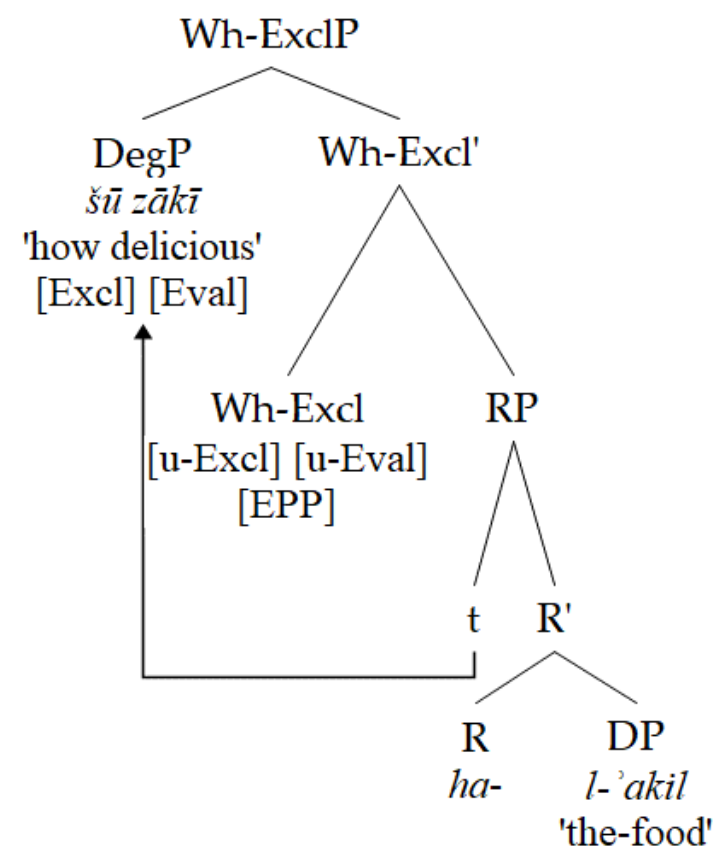


In both structures, Excl serves as a probe which searches for a c-commanded goal to agree with. The only goal is AP 'delicious' due to its valued [EVAL] and [EXCL] features; thus, Excl agrees with it. In consequence of Agreement, the values of the features on AP 'delicious' are copied onto Excl, and the [EPP] feature is satisfied by either merging of PRN $s \bar{s}$ 'how' or DegP $s \bar{u} z \bar{a} k \bar{l}$ 'how delicious'. The given representations explain why ExclPs allows only the word order $\breve{s} \bar{u}$ AP $h a$-DP. Furthermore, the demonstrative-like $h a$ - is argued to be the lexicalization of $\mathrm{R}^{16}$. Analyzing $h a$ - as a prefix in $\mathrm{R}$, rather than a Dem, accounts for its obligatory presence in wh-ExclP but not in declaratives. The optionality of Dem $h a$ - in declaratives can be supported not only by nominal sentences such as $(23 \mathrm{a}, \mathrm{b})$ above but also by verbal ones like (27) with an indication of its status as a demonstrative head (for proposals of Arabic demonstratives, see Al-Bataineh, 2020:24, and references therein), that is, the referent in declaratives can be either a DP 'the food' or a DemP headed by a Dem ha- 'this':

\section{7) 'ajab-n-i (ha)-l-'akil \\ liked-NW ${ }^{17}$-me (this)-the-food \\ 'I liked this food.'}

Further support of the status of $h a$ - as the lexicalization of $\mathrm{R}$ in ExclPs can also be drawn from its form and position. Whereas the Dem $h a$ - in declaratives can have the full form hāta 'this', the $\mathrm{R}$ $h a$ - is always a bound morpheme, and it must precede the DP, in contrast with the Dem häta 'this' which can either precede or follow the DP. Analyzing $h a$ - as a Relator not only explains the obligatoriness of $h a$ - and its differences from the regular Dem, but also clarifies other realizations of $\mathrm{R}$ (e.g., $\underline{d} \bar{a}$ in $h a b b a \underline{d} \bar{a}$ 'how appreciative,' and the prepositions $l a$ - in Voc-ExclPs and $b i$ - in templatic V-ExclPs, to be explained below).

Regarding the selectional properties of $\check{s} \bar{u}$ 'how' and ayš 'what.' Let us reconsider (24a,b) and (25), repeated as $(28 \mathrm{a}, \mathrm{b})$ and (29):
28) a. $\check{s} \bar{u} \quad z \bar{a} k \bar{l} \quad(*(h a)-l$-'akil $)$
how delicious (*(PRFX)-the-food)
'How delicious (the food is)!'
$\begin{array}{ll}\text { b. *ayš zāki } & *(h a)-l \text {-'akil } \\ \text { what delicious } & *(\text { PRFX)-the-food }\end{array}$
'How delicious (the food is)!'
29) $\check{s} \bar{u} / \quad$ ayš $\quad *(h a)-l$-'akil
$(* z \bar{a} k \bar{l})$
what/ what *(PRFX)-the-food
(*delicious)
'What a (delicious) food it is!'

(28a,b) show that only š́ 'how' selects an AP which can be followed by an optional ha-DP ${ }^{18}$, and (29) demonstrates that both $\check{s} \bar{u}$ 'what' and ayš 'what' select $h a$-DP which cannot be followed by an

\footnotetext{
${ }^{16} \mathrm{~A}$ similar structure exists in Mandarin Chinese in which zhème/nàme 'this.ME/that.ME' are used with zěnme 'how' to form Excls (Badan \& Cheng, 2015).

17 This - $n$ - (called in Arabic grammar nūn alwiqāya 'preventive n', abbreviated here as NW) is obligatorily inserted after the verb only when it is followed by the 1 SG.SUB/OBJ/POSS ' $\mathrm{I} / \mathrm{me} / \mathrm{my}$.'

${ }^{18}$ The possibility of the ellipsis process of $h a$-DP in (24a) above indicates that $\mathrm{R}$ in Wh-ExclPs has the two variants $h a-$ and $\varnothing$. The choice between these two variants depends on the presence of DP, that is, when the DP is present, R is realized as $h a$ - simply because it has a suitable host to attach to, but when the DP is elided, it has the null variant. An alternative analysis is to propose that the $\mathrm{R}$ has one form $h a$ - which must attach to the DP before the ellipsis takes place to avoid a violation of the Stray Affix Filter “Affixes must have phonologically overt hosts" (Lasnik, 1990, 1995, cited in Markman,
} 
AP. That is, when the AP is present, only $\check{s} \bar{u}$ ' 'how' is allowed, and when the AP absent, then there is a choice between $\check{s} \bar{u}$ and ays. These facts indicate that the presence of AP determines the choice of the $w h$-form, and its absence gives equal opportunity for both $w h$-forms to be utilized. To account for these peculiarities, let us first highlight the fact briefly discussed above that $\check{s} \bar{u}$ and the AP $z \bar{a} k \bar{l}$ do not always form a single constituent because they can be separated by the copula kān 'was', as in (30):

$$
\begin{array}{llll}
\text { 30) } \check{s} \bar{u} & k \bar{a} n & z \bar{a} k \bar{l} & \text { ha-l-'akil } \\
\text { how was } & \text { delicious } & \text { this-the-food } \\
\text { 'How delicious (the food was)!' }
\end{array}
$$

(30) indicates that $\check{s} \bar{u}$ and the AP are not obligatory adjacent. Strangely enough, $\check{s} \bar{u}$ and ayš must be adjacent to the $h a$-DP as the insertion of the same element between the two constituents leads to ungrammaticality in (31):

$$
\begin{aligned}
& \text { 31) } \check{s} \bar{u} / \text { ay } \check{s} \text { *kān ha-l-'akil } \\
& \text { what/ what *was this-the-food } \\
& \text { '*What a food it was!' }
\end{aligned}
$$

To account for the intricate adjacency requirements, I argue that the copula kān 'was' is a focus particle, rather than an auxiliary verb in V or T simply because Excls are not finite clauses. This argument is based on several pieces of evidence. First, while 'was' is allowed for emphasis, its present and future counterparts are not allowed in JA Excls (and also in MSA, see, e.g., Ya' iss, 2001:423424). Second, unlike canonical $k \bar{a} n$ 'was', the focus marker $k \bar{a} n$ cannot combine with sentential negation because "the location of the negative projection is relative to the projection that carries the temporal information of the clause" (Benmamoun, Abunasser, Al-Sabbagh, Bidaoui, \& Shalash, 2013:84, see also Shlonsky, 1997; Soltan, 2007). Consider the contrast between the declarative and the exclamative in $(32 \mathrm{a}, \mathrm{b})$ :

$\begin{array}{clll}\text { 32) a. } \boldsymbol{m} \overline{\boldsymbol{a}} & k \bar{a} n-i \check{\boldsymbol{s}} & z \bar{a} k \bar{\imath} & h a-l \text {-'akil } \\ \text { NEG } & \text { was-NEG } & \text { delicious } & \text { this-the-food }\end{array}$

'The food was not delicious.'

$\begin{array}{lllll}\text { b. } \check{s} \bar{u} & * \boldsymbol{m} \overline{\boldsymbol{a}} & k \bar{a} n-{ }^{*} i \check{s} & z \bar{a} k \bar{l} & \text { ha-l-'akil } \\ \text { how } & * \text { NEG } & \text { was-*NEG } & \text { delicious } & \text { this-the-food } \\ \text { ‘*How delicious the food }\end{array}$

'*How delicious the food was not.'

Third, the focus marker kān has one fixed position between the RP and Excl, that is, it cannot intervene between the two relata of RP as in (33a), but the canonical kān can exist between the subject and the predicate in declaratives as in (33b):

33) a. $\check{s} \bar{u} \quad z \bar{a} k \bar{l}$ *kān ha-l-'akil
how delicious *was this-the-food
'How delicious the food was!'
b. $z \bar{a} k \bar{c} \quad \boldsymbol{k} \overline{\boldsymbol{a}} \boldsymbol{n} \quad$ ha-l-'akil
delicious was this-the-food

'The food was delicious!' 
Fourth, unlike equivalent main clauses in (34a,b), Excls with 'was' (actually even without the copula) cannot exist in or with a temporal adverbial clause as in (35a,b), respectively, because "temporal adverbial clauses are derived by movement of a TP-internal operator to the left periphery" (Endo \& Haegeman, 2019:11):

\begin{tabular}{|c|c|c|c|}
\hline $\begin{array}{l}\text { 34) a. lamma } \\
\text { when }\end{array}$ & $\begin{array}{ll}z \bar{a} k \bar{l} & l \text {-'akil } \\
\text { delicious } & \text { this-the-food }\end{array}$ & & \\
\hline 'When the & d was delicious, [I used to eat more]! & & \\
\hline $\begin{array}{l}\text { b. lamma } \\
\text { when }\end{array}$ & $\begin{array}{ll}\text { kunt } & \text { bi-balad- } \bar{l} \\
\text { was.1SG.SBJ } & \text { in-home country-my }\end{array}$ & $\begin{array}{ll}k \bar{a} n & z \bar{a} k \bar{l} \\
\text { was } & \text { delicious }\end{array}$ & $\begin{array}{l}\text { l-'akil } \\
\text { the-food }\end{array}$ \\
\hline
\end{tabular}

$\begin{array}{cllll}\text { 35) a. *lamma } & \check{s} \bar{u} & k \bar{a} n & z \bar{a} k \bar{l} & \text { ha-l-'akil } \\ \text { when } & \text { how } & \text { was } & \text { delicious } & \text { this-the-food }\end{array}$

'*When how delicious the food was!'
b. *lamma
kunt
bi-balad- $\bar{\imath}$
$\check{s} \bar{u} \quad k \bar{a} n \quad z \bar{a} k \bar{l}$
ha-l-'akil
when was.1SG.SBJ in-home country-my how was
'*When I was in my home country, how delicious the food was!'

Fifth, the copula in Excls does not affect case assignment; that is, it is deprived of its ability to assign the accusative case to the predicate in nominal sentences. The peculiar syntactic behavior of the focus marker in not assigning case is more apparent in MSA as it is richer in morphological inflections than JA (see, e.g., Ya' '̄sh, 2001:424, for illustrative examples). However, the last issue to consider is that the phi-features carried by the copula $k \bar{a} n$ 'was' in Excls does not necessarily impose that it is a $\mathrm{T}$ element because the phi-features originate in the left periphery, rather than in $\mathrm{T}$ (Chomsky, 2001, 2008; Richards, 2007). This view can be supported further by other studies analyzing the copula as focus or topic marker in English (e.g., O'Neill, 2015:210, and the references therein) and as a focus operator in Iraqi Arabic (Bakir, 2019), rather than T. Agreeing with Bakir (2019:126), "the focus operator [in our case kān 'was'] is overtly spelled out with phi features that get valued via agreement with a c-commanded relevant goal [in the given examples, the DP "the food']". The independency between finiteness and $T$ can be further supported by the fact that "complementizers show subject agreement inflection [...] in a range of language families" (O'Neill, 2015:357).

Returning to the adjacency relations between the two relata in RP exemplified in (28a,b) and (29) above, the derivations in (36) show that the focus operator realized as $k \bar{a} n$ 'was' can originate between RP and Excl as this position does not affect the structure because the [EPP] feature on Excl is satisfied by the external merge of the exclamative pronoun $\breve{s} \bar{u}$, but it cannot originate between the exclamative pronoun $\check{s} \bar{u} /$ ays 'what' and the R' as it blocks the movement of the exclamative pronoun to spec-ExclP, as shown in $(36 \mathrm{a}, \mathrm{b})$, respectively (to simplify exposition, the FocP is not shown in (36b)):

36) a.

b. 

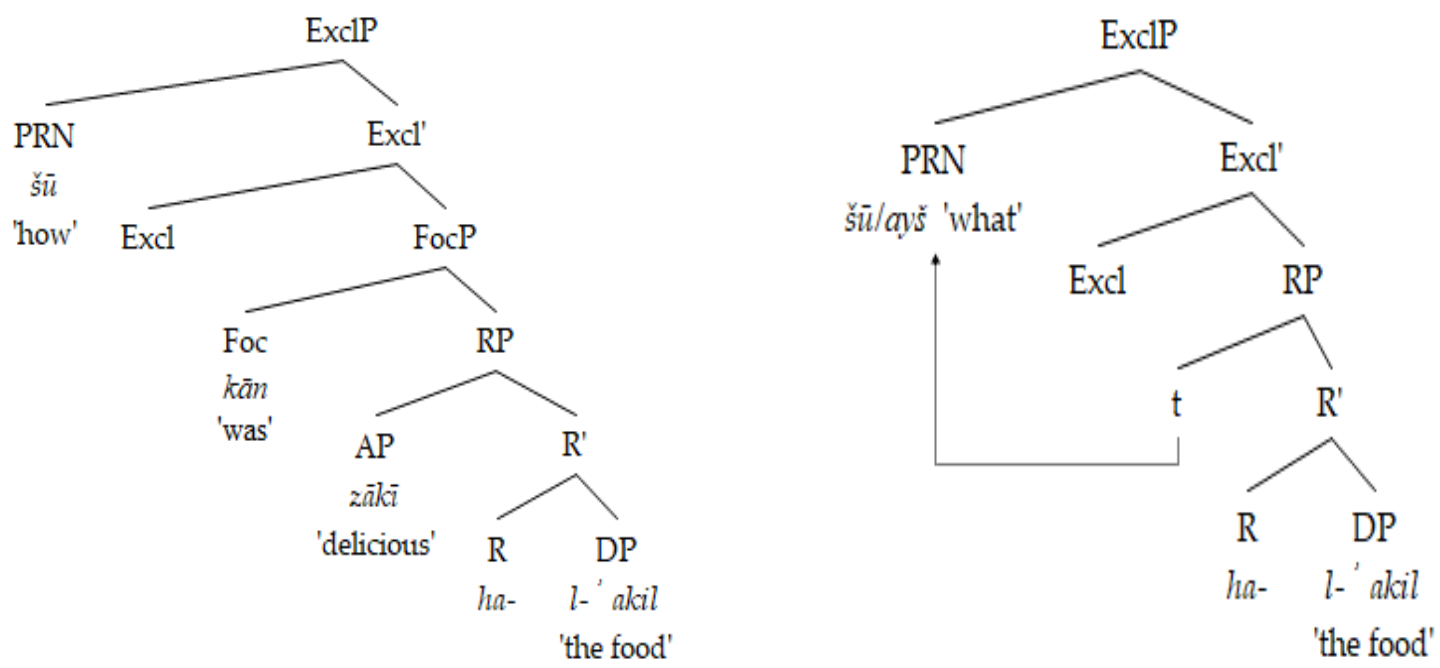

In (36a), Excl serves as a probe which searches for a c-commanded goal to agree with. The only goal is AP 'delicious'; thus, Excl agrees with it. In consequence of Agreement, the values of the [EVAL] and [EXCL] features of AP 'delicious' are copied onto Excl, and the [EPP] feature is satisfied by the external merge of $\breve{s} \bar{u}$ 'how'. In (36b), while the [EVAL] and [EXCL] features can be copied on Excl by Agree, the [EPP] feature cannot be satisfied by external merge of an exclamative pronoun as that would yield two exclamative pronouns with the same identity (i.e., the same semantic and syntactic properties); hence, the only way to satisfy the [EPP] feature is by moving the exclamative pronoun from spec-RP to spec-ExclP. Therefore, the projection of FocP is not allowed. This explains not only the obligatory absence of AP in (36b) (and other relevant types of ExclPs discussed below) but also clarifies the adjacency required between the $w h$-elements and $h a$-DP. As argued above, the AP must be adjacent to the DP it associates with, and a syntactic element such as the copula $k \bar{a} n$, an interjection (e.g., 'awāh 'Ouch!,' 'ihi 'Hooray!,' or 'uffin 'Damn!') or an adjunct cannot intervene between the moved exclamative pronoun and the DP.

\subsection{Voc-Excls in MSA}

In section (3), a differentiation is drawn between VocPs and Voc-ExclPs based on a number of syntactic properties (i.e., case assignment and selectional requirements) and semantic features (i.e., [REFERENTIALITY], [EVAluATIVE], [ANIMACY] and [DEGREE]). In addition to examples from MSA mentioned above (e.g., 13b, repeated as 37a below), other ones also exist in JA exemplified in (37b):

$$
\begin{array}{cll}
\text { 37) a. } y \bar{a} & \text { la-jamāl-i } & a l-t a b \bar{l}^{\prime} a t-i \\
\mathrm{O} & \text { PREP-beauty-GEN } & \text { the-nature-GEN }
\end{array}
$$

'How captivating the beauty of nature is!'
b. $y \bar{a} b \bar{a} y$
'a-ḥalāwt-ik
$\mathrm{O}$ PREP-beauty-your.FEM

'How irresistibly attractive your beauty is!'

In both varieties, Voc-ExclPs are initiated by a vocative particle (i.e., $y \bar{a}$ and $y \bar{a} b \bar{a} y$ ), and the exclamative expression is preceded by a preposition (i.e., la and ' $a$ ). Apart from the different realizations of vocative particles and prepositions, the two constructions seem syntactically identical, that is, they follow the same pattern (i.e., vocative particle-preposition-DP). To provide a plausible analysis of Voc-ExclPs, two peculiarities need to be clarified, namely, the absence of a predicative 
AP and the presence of a semantically empty preposition. In other words, two questions arise in these constructions: (i) Why does the presence of AP lead to ungrammaticality? (ii) Why does a preposition exist although it is not semantically required? For reasons of space, the analysis below focuses on MSA, assuming that JA has the same arguments and derivations based on the fact that both have the same order of vocative particle-preposition-DP.

Consider the declarative equivalent of (38) below, and notice that the presence of the same vocative particle $y \bar{a}$ or the preposition la- leads to ungrammaticality:

$$
\begin{array}{cllll}
38)(* \boldsymbol{y} \overline{\boldsymbol{a}}) / & (* \boldsymbol{l a}) & \text { jamāl-u } & \text { al-țabì 'at-i } & \text { 'akk } k \bar{a} \underline{d}-u-n \\
\mathbf{O} / & \text { PREP } & \text { beauty-NOM } & \text { the-nature-GEN } & \text { captivating-NOM-N }
\end{array}
$$

'The beauty of nature is captivating.'

The fact that declaratives cannot be preceded by either the vocative particle or the preposition indicates that the syntax of Voc-ExclPs does not follow the same mechanisms adopted in clauses, that is, an analysis of the AP 'akka $\underline{d} u n$ 'captivating' cannot be argued to be originated within the TP domain simply because it is obligatory absent in Voc-ExclPs, and the DP cannot be the complement of the preposition because the preposition is not semantically required in declaratives and its presence makes the sentence ill-formed. A straightforward and plausible account of Voc-ExclPs such as (37a) can be argued to be represented as in (39):

39)

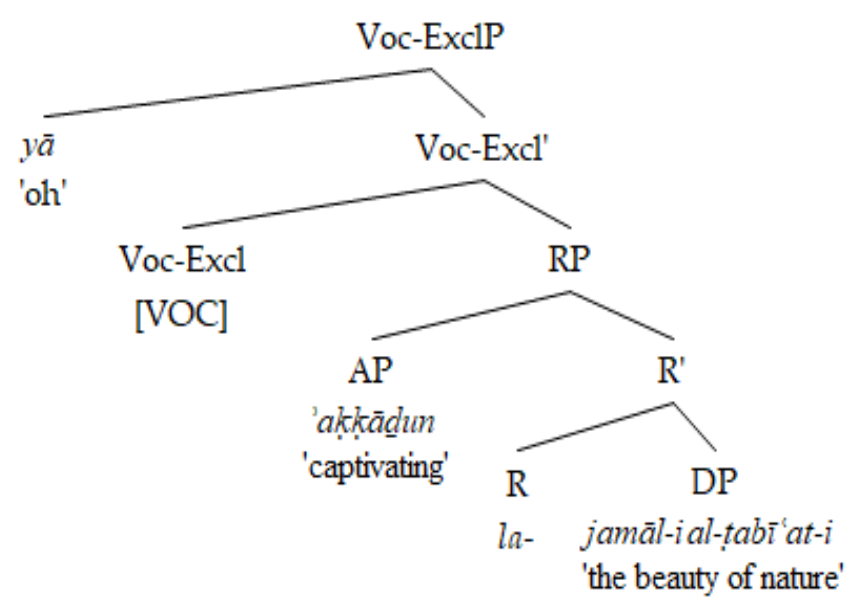

Excl serves as a probe and agrees with the goal AP 'akkāe 'captivating'. In consequence of Agreement, the values of the [EVAL] and [EXCL] features of AP 'captivating' are copied onto Excl, and the [EPP] feature is satisfied by external merge of $y \bar{a}$ 'oh' rather than movement of the AP because Voc-Excl carries the feature [VOC] that requires the specifier of Voc-ExclP to be a vocative particle. After the processes of valuation and agreement take place, the AP gets null spellout by the haplology rule: an avoidance mechanism that eliminates one of the two identical forms (i.e., phonemic (e.g., Wong, Huang, \& Chen, 2018), morphemic (e.g., Faust, 2018), semantic (e.g., Apresjan, 1977) identical elements). This mechanism which is motivated by economy can also be triggered in circumstances in which two forms have identical syntactic features. According to Neeleman \& Van de Koot (2006:700) (see, e.g., Wong et al., 2018 for similar views, and Hiraiwa, 2010 for more references):

Given that the spell-out rules relate morpho-syntactic objects to their phonological form, one would expect to find cases in which deletion or suppletion is triggered by syntactic features even though the morphemes affected are not phonologically identical in isolation. 
Based on the distinction between the vocative particle in VocPs and Voc-ExclPs summarized in the beginning of this section, and also on the semantics of the particle which denotes exclamation and evaluation, I argue that the features [EVAL] and [EXCL] exist not only in the AP 'captivating' but also in the vocative particle as well. Since both $y \bar{a}$ and the AP 'akk $\bar{a} \underline{d}$ 'captivating' carry the same features, the haplology process requires deletion (or suppletion as exemplified in the last subsection) of one of the two exclamative expressions. The AP is deleted because the Voc-Excl requires an element with the [VOC] feature in its specifier position (i.e., $y \bar{a}$ 'oh'). Thus, the derivation in (39) accounts for the obligatory absence of the AP in Excls but not in their equivalent clauses. Moreover, the meaningless preposition $l a$ - is shown to be the overt realization of $\mathrm{R}$ since it is selected by $y \bar{a}$ ' oh', and that explains the absence of this preposition in clauses that do not have the same syntax as tenseless Voc-ExclPs. The last issue to be highlighted is that the referent is assigned genitive case if the spurious preposition is present; otherwise, it is marked accusative by the vocative particle which carries the valued [ACCCase] feature (for more details on this operation, see Al-Bataineh, 2020)

\subsection{V-ExclPs in MSA}

This section explores the two sub-strategies involved in V-ExclPs in Arabic ${ }^{19}$, namely, the use of evaluative verbs and the utilization of morphological templates. In contrast with other similar VExclPs in Spanish (Gutiérrez-Rexach, 2001), for example, which involve the insertion of a verb before the AP, Arabic V-ExclPs require the AP to change its syntactic category to be verbal, although not entirely verbal as the next subsections show.

\subsubsection{V-Excls: evaluative verbs}

Evaluative verbs can be categorized into two groups according to their complexity: (i) simple verbs

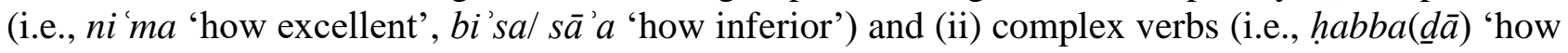
appreciative', la habba( $\underline{d} \bar{a})$ 'how depreciative'). Both categories show several peculiarities that distinguish them from other verbs in other structures. In addition to their fixed word order due to the obligatory movement of AP and their phrasal, rather than clausal, nature (as evidenced in the ungrammaticality of the insertion of an auxiliary in T), these categories demonstrate verbal and nominal properties simultaneously which led to a debate among grammarians concerning their syntactic category ${ }^{20}$ (for details, see Almasā' $1 \overline{1} d \&$ Almalk, 2015, and references therein). Consider, for example, that ni 'ma 'excellent' behaves like a nominal as it can be the complement of a preposition in (40a) or a vocative particle in (40b), and it cannot be conjugated (cf. *yan 'umu '3.SG.SBJ in the present tense'):
40) a. $m \bar{a}$ zayd-u-n
bi-ni'ma
ar-rajul-u
not Zayd-NOM-n PREP-excellent
the-man-NOM
'Zayd is not the excellent man.'

\footnotetext{
19 The given discussion below focuses on MSA since it is richer than colloquial varieties in the number of lexical expressions used in V-ExclPs. For example, in JA only the verb $n i$ ' $m a$ 'how excellent' and the template $m \bar{a}$ 'af'ala exist.

${ }^{20}$ According to Bresnan (1997:3), "mixed categories are very common crosslinguistically [...] in many languages mixed category constructions are headed by words which appear to be morphologically ambiguous or neutral between the two categories of the mixed construction. The Italian infinitival noun is an example being either a nominal or a verbal form."
} 

b. $\boldsymbol{y} \overline{\boldsymbol{a}} \quad n i ' m a$
almawlā
wa $\quad \boldsymbol{y} \overline{\boldsymbol{a}}$
ni'ma
an-nașīr-u
O excellent protector
and $\mathbf{O}$ excellent
the-helper-NOM

'(Allah is) the most excellent Patron and the most excellent Helper.'

(Almasā '̄id \& Almalk, 2015:8)

And it also behaves like a verb in carrying number and gender features that agree with the subject, as exemplified in $(41 \mathrm{a}, \mathrm{b})$, in addition to showing tense (i.e., past tense) and taking an argument:

\section{1) a. $n i{ }^{\prime} m-\overline{\boldsymbol{a}}$ excellent-DUAL rajul-ayn 'How excellent these two men are!'
b. $n i$ 'ma-t
al-fatat-u
excellent-SG.FEM
the-girl-NOM
'How excellent the girl is!'

(Almasā̄̄ì \& Almalk, 2015:8)

The evaluative expressions discussed in this section cannot be considered as verbs since they do not denote events, and they cannot be considered as nouns because they do not denote things. As shown above, syntactically, these expressions are not verbs as they can be complements of prepositions or vocative particles and cannot be conjugated, and they are not nouns as they show tense and take arguments. This raises a question regarding their categorial status. Depending on the fact that these evaluative expressions are used to denote states or properties to qualify the referent in Excls, I argue that they originate as AP due to their nominal features, and then they get some, but not all, verbal features from V-Excl. This argument shows why evaluative verbs are semantically adjectives and syntactically behave as nominal and verbal simultaneously. This is in line with Chomsky's (1970, cited in Baker, 2003:2)) view of adjectives as [+N, +V] and Baker's (2003:21) proposal "that adjective is essentially the "default" category. It appears in a nonnatural class of environments where neither a noun nor a verb would do". 21

To account for the given perplexing intricacies of evaluate verbs ${ }^{22}$, the paper argues that the evaluative and exclamative functions of these expressions in ExclPs cause their peculiar behavior. That is, since these verbs are limited to the expressive function, they are supposed to be different from other verbs serving other functions at the clausal level. In brief, arguing that the syntax of V-ExclPs follows that of other types explained above provides a straightforward account for their nominal and verbal properties, obligatory initial position and existence only at the phrasal non-TP level. To illustrate, consider (42) and its derivation in (43a,b):

$$
\begin{array}{ll}
\text { 42) } n i \text { 'ma } & \text { ar-rajul-u } \\
\text { excellent } & \text { the-man-NOM } \\
\text { 'How excellent this man is!' }
\end{array}
$$

\footnotetext{
${ }^{21}$ The binary system [+/-N, +/-V] adopted by Chomsky (1970) and Baker (2003) is argued for more than 800 years ago by traditional Arab grammarians who maintained that Arabic words can be nouns or verbs (i.e., lexical categories), or particles (i.e., functional categories), as stated in the first line in the Alfiyyah of Ibn Malik (Aqeel, 1980).

${ }^{22}$ Agreeing with the majority of Arabic grammarians, I consider evaluative expressions in this section and the following one to be more verbal, rather than nominal, in nature.
} 
43) a.

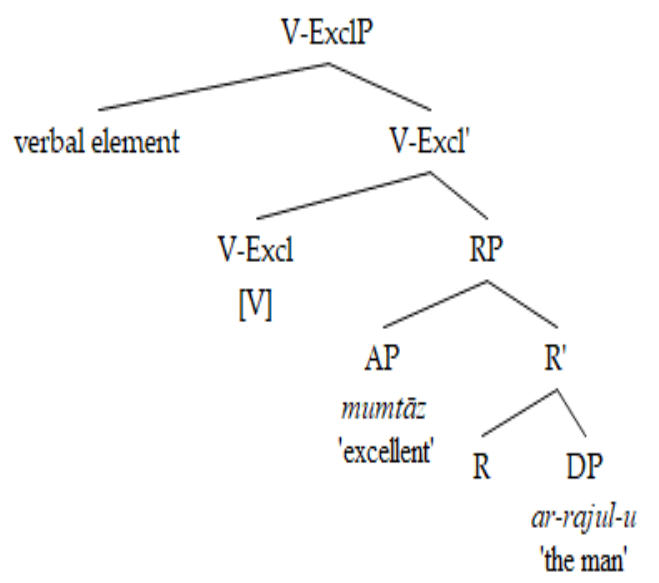

b.

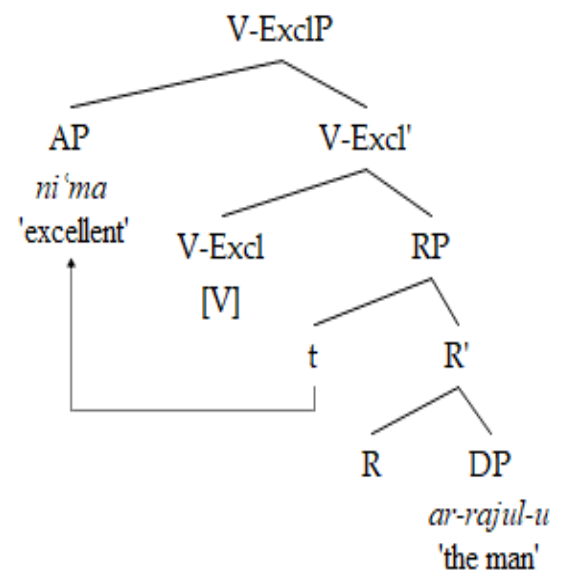

The V-Excl requires a verbal element to be in its specifier position due to its [V] feature. As demonstrated in derivation (43a), the AP (i.e., the exclamative quality ascribed to 'the man' which is assumed to be mumtā $z$ 'excellent' (or any general positive trait that varies depending on the context)) cannot move in its current form and needs to be verbal by a suppletion process that provides a specific verbal form that must be "an overt form that unambiguously spells out the features unaffected by suppletion" (Neeleman \& Van de Koot, 2006:706) ${ }^{23}$. That is, the adjectival element changes by suppletion to an overt form that retains the [EXCL] and [EVAL] features, and it is verbal at the same time. The verbal form can be either an evaluative verb as in the given example or a form that is molded according to specific morphological templates that express exclamation and evaluation, as discussed in the following subsection. The change from the adjectival mumtāz 'excellent' to the partially verbal form ni ' $m a$ 'excellent' enables the AP to move to spec-VExclP to satisfy the [EPP] feature on VExcl. The result of this change is a partially verbal expression that has some, but not all, properties of a regular verb (and carries some nominal properties as well). This claim explains why the V-Excl expression $n i$ ' $m a$ has the peculiarities mentioned above. In a similar vein, the syntax of complex evaluative verbs follows the same derivation. Consider (44) represented as $(45 \mathrm{a}, \mathrm{b})$ :

44) $h a b b a-\underline{d} \bar{a} \quad$ al-rajul-u

liked-PRFX the-man-NOM

'lit: I liked this man (for his good traits). = How appreciated this man is!'

\footnotetext{
${ }^{23}$ For supportive phenomena from Dutch and MSA, see Neeleman \& Van de Koot (2006, and references therein).
} 
45) a.

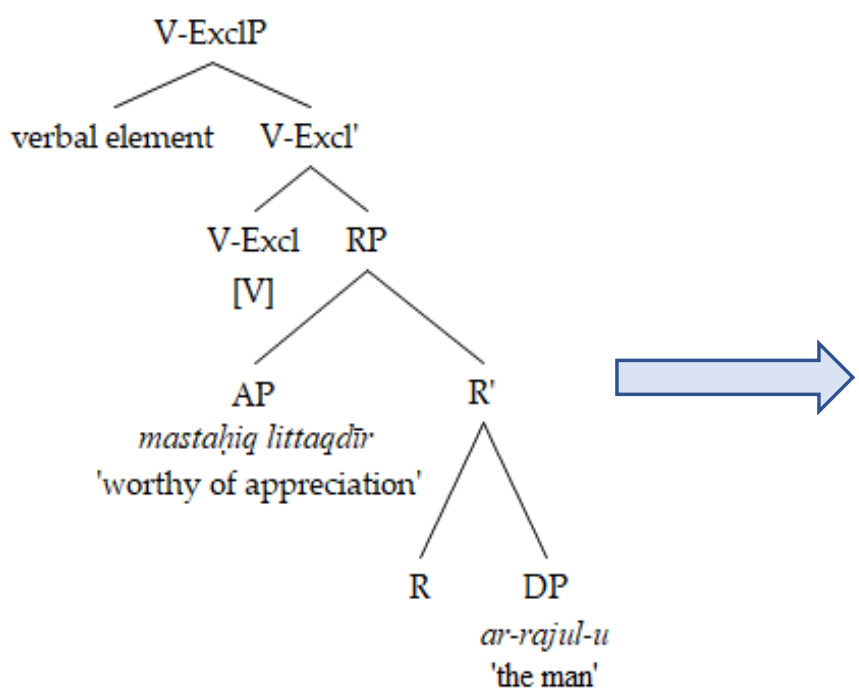

b.

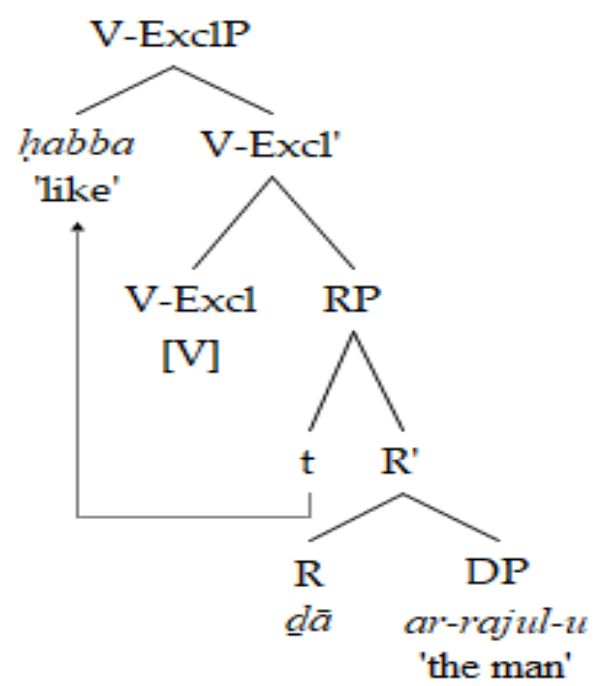

The AP mastahiq littaqdīr 'worthy of appreciation' undergoes the same suppletion process and moves to spec-VExclP for the same reasons explained above. The only difference between these derivations and $(43 \mathrm{a}, \mathrm{b})$ is that the $\mathrm{R}$ head is lexically realized by the optional suffix - $\underline{a} \bar{a}$ that resembles $h a$ - in $w h$ ExclPs in the sense that it cannot be analyzed as a demonstrative because it cannot follow the DP 'the man' (*habba alrajulud $\overline{\boldsymbol{a}}$ ), and it cannot be in the full form (*habba hä $\underline{d} \boldsymbol{a}$ ). Further evidence of its position in $\mathrm{R}$ is that it cannot be associated semantically with the evaluative verb since neither the lexical entry of the habba 'liked' requires $-\underline{d} \bar{a}$ nor it is affected by its presence. The attachment of $\underline{d} \bar{a}$ to the evaluative verb is syntactically triggered, that is, unlike $h a$ - which needs a nominal host, $\underline{d} \bar{a}$ needs a verbal host. However, the last point to be mentioned is that in these constructions, the DP is marked nominative by default due to the absence of any case assigner. This phenomenon is not limited to Arabic; it also exists in other languages such as Icelandic and Hindi in which "nominative is preferable as the less marked case [in] an imperfect checking domain" (Woolford, 2003:542-543).

\subsubsection{V-Excls: morphological templates}

This strategy demands that APs be formed according to specific morphological templates, namely, fa' 'ula, 'af'il bi-, $m \bar{a}$ ' af'ala which act as frames or molds that shape the word structure of the property exclaimed about. Consider the change of the morphological form of hasan 'good' in the exclamative constructions in (46a-c):

46) a. hasuna Zayd-u-n
excellent. EXCL
'How excellent Zayd is!'
b. 'ahsin
bi-Zayd-i-n
excellent. EXCL
PREP-Zayd-GEN-n
'How excellent Zayd is!'
c. $m \bar{a}$ 'ahsana
Zayd-a-n
PTCL excellent. EXCL
Zayd-ACC-N
'How excellent Zayd is!' 
Notice that the change of the morphological form of hasan 'good' does not correlate with a change in the meaning of the exclamative, that is, the three templates have the same function of providing the expressive meaning of 'how excellent Zayd is!'. Regarding the categorial status of these templates, grammarians disagree whether they are verbal or nominal because these templates share the syntactic properties of verbs and nouns simultaneously. To illustrate, the template $m \bar{a}$ 'af'ala in (46c) is verbal because it shows tense (i.e., past tense), takes arguments (i.e., $m \bar{a}$ as subject and Zayd as object), demonstrates transitivity (i.e., it assigns accusative case to its complement Zayd) and requires nūn alwiqāya 'preventive - $n$ ' (explained in footnote (14) above) if followed by first-person singular pronoun ('a 'lama-n- $\bar{\imath}$ 'taught-n-me' vs., *mu 'allim-n- $\bar{\imath}$ 'teacher-n-my'). At the same time, this template shows several nominal properties; it can be used in the diminutive form; the middle vocalic sound of its triliteral root changes into a semivowel (e.g., the middle [a] vowel in qāma 'stand' changes to [w] in the Excl $m \bar{a}$ 'aqwama 'how straight!' although no change takes place in the verb

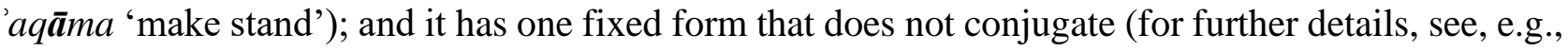
'A bū Albarkāt Al'Anbārī, 1982:126-148).

The peculiarities above stem from the fact these templates are used exclusively in Excls which have syntactic structures distinct from clauses; that is, these templates are not fully verbal because they do not originate in $\mathrm{V}$ and, consequently, associated with little $\mathrm{v}$ like other verbs in TPs. However, the approach adopted in this paper may account for their mysterious behavior. (46a) may have the representation in $(48 \mathrm{a}, \mathrm{b})$ :
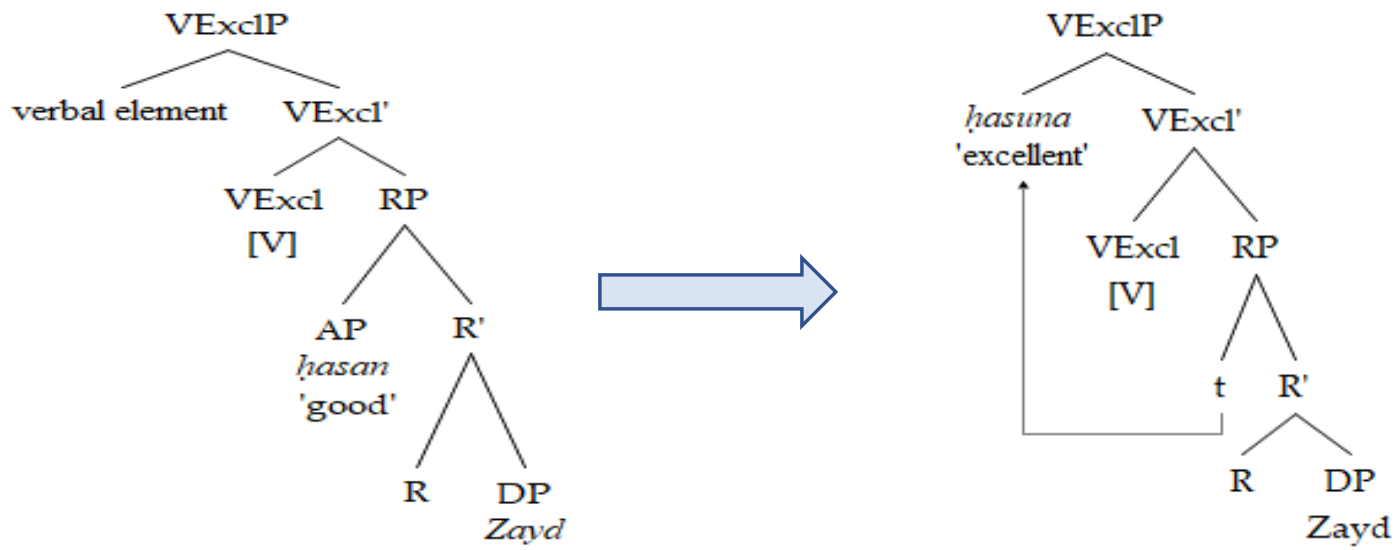

As discussed in the previous subsection, the VExcl requires a verbal element to be in its specifier position due to its [V] feature. The AP hasan 'good' cannot move in its current form and needs to be verbal by a suppletion process that retains the [EXCL] and [EVAL] features and the semantics of the AP. The verbal form is molded according to the morphological template fa 'ula that changes the adjectival hasan 'good' to the partially verbal form hasuna 'how excellent'. This change enables the AP to move to spec-VExclP to satisfy the [EPP] feature on VExcl. The result of this change is a partially verbal expression that has only some of the syntactic properties of a regular verb (and simultaneously some nominal properties). In a similar vein, the other templatic forms in $(46 \mathrm{~b}, \mathrm{c})$ have the representations in $(48 \mathrm{a}, \mathrm{b})$, respectively: 
48) a.

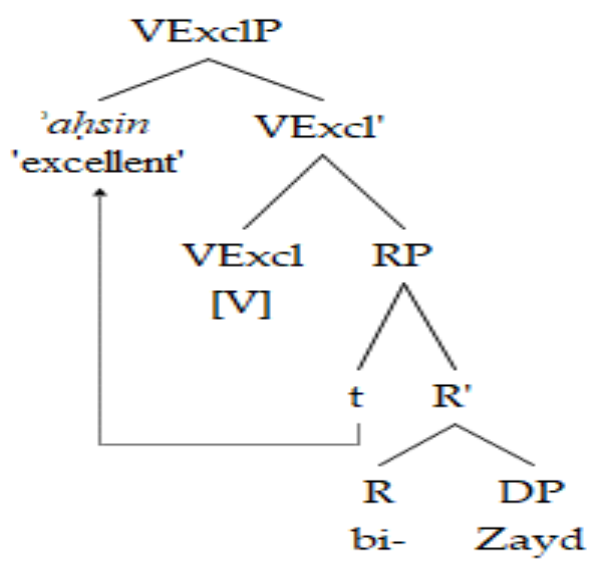

b.

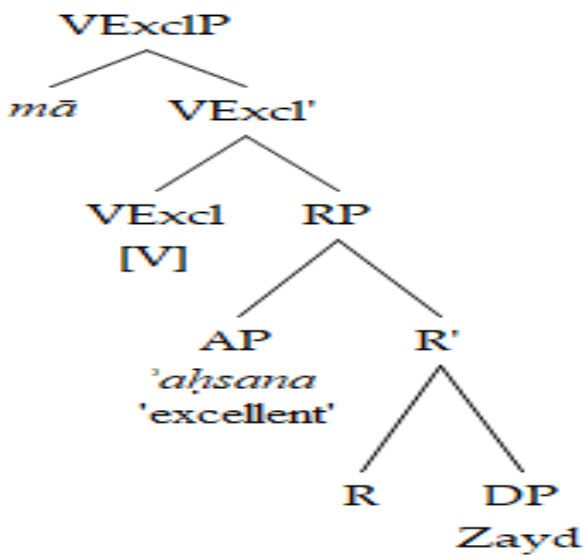

(48a) shows that the AP hasan 'good' changes into 'ahsin 'excellent' according to the templatic form 'af' $i l$ bi-for the reasons given above, and the meaningless preposition $b i$ - is shown to be the realization of $\mathrm{R}$. In support of this derivation, 'ahsin which looks like an imperative verb allows only the spurious preposition $b i$-, rather than the semantically required one 'ila 'to', and it does not agree with the addressee, as the contrast between the declarative and exclamative constructions show in (49a,b), respectively ${ }^{24}$ :

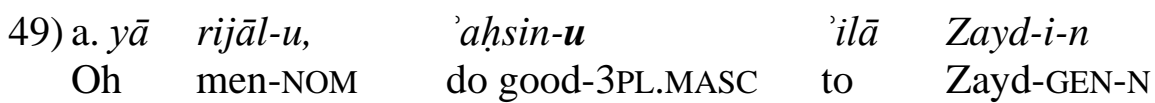

'Oh men, do good to Zayd.'
b. $y \bar{a} \quad r i j \bar{a} l-u$,
'aḥsin-*u
bi-Zayd-i-n
Oh men-NOM
do good-*3PL.MASC
PREP-Zayd-GEN-N

The representation in (48b) follows the same syntax like in (48a) except for the presence of the particle $m \bar{a}$ in spec-VExclP which prevents the movement of AP 'ahsana 'excellent'. This derivation triggers two related questions: how does the external merge of the particle $m \bar{a}$ satisfy the [V] feature on VExcl? Why does the AP hasan 'good' undergo suppletion despite the merge of $m \bar{a}$ ? The answer to these questions lies in the categorial status of both the particle and the AP. I argue that both are mixed/hybrid expressions due to the different syntactic features they carry. The particle has $[\mathrm{WH}]$ and $[\mathrm{V}]$ features, and the AP has $[\mathrm{V}]$ and $[\mathrm{N}]$, simultaneously. To illustrate, consider the two syntactic behaviors of the particle in $(50 \mathrm{a}, \mathrm{b})$, and notice that in (50a) it has [WH]; hence, it cannot assign case to the following DP, whereas in (50b) it assigns accusative case to the DP 'the sky' (and the AP 'beautiful' gets accusative case by concord with DP) due to its [V] feature:
50) a. $m \bar{a}$ 'ajmal-u
as-samä'-i
what most beautiful-NOM the-sky-GEN
'What is the most beautiful object in the sky?'
b. $m \bar{a}$ 'ajmal-a as-sama $\bar{a}$ '-a
PTCL beautiful. EXCL-ACC the-sky-ACC
'How beautiful the sky is!'

\footnotetext{
${ }^{24}$ Other arguments that differentiate between the imperative form and the exclamative one are overlooked here due to space (see, e.g., Ya'ish (2001:420) for arguments related to responses and conditional clauses).
} 
The same element $m \bar{a}$ has nominal and verbal features simultaneously as evidenced in its status as a wh-phrase in (50a); hence, it does not affect case assignment of the Construct State construction, and as a transitive particle which assigns the accusative case to the DP in (50b). The hybrid nature of $m \bar{a}$ shows that it has the semantics of 'how' and the syntax of a transitive verb in the sense that "the two categories are folded together and overlaid as a single [...] head" (Bresnan, 1997:6). For the same element to have both nominal and verbal properties is common in other Arabic constructions as well. Consider how the nominal salb 'depriving' in (51) requires two VP constituents and assigns the accusative case to both of them:

\section{1) salb-u zayd-i-n ar-rajul-a maal-a-hu depriving-NOM Zayd-GEN-N the-man-ACC money-ACC-his "Zayd's depriving the man of his money"}

(Fassi Fehri, 1993:247)

Similar to $m \bar{a}$, the AP is also a mixed element, that is, it has both [V] and [N] features as evidenced in its morphological form that resembles a transitive verb and a superlative form of an adjective, and also in its syntactic behavior as an adjective that is marked accusative by the particle $m \bar{a}$ and as a verb by taking two arguments; the particle $m \bar{a}$ as a subject and the following DP as an object. However, analyzing $m \bar{a}$ as a transitive particle required by the [V] feature on VExcl deviates from the traditional view that $m \bar{a}$ means 'something (that caused Zayd to be excellent).' The analysis of $m \bar{a}$ as a particle rather than an indefinite noun is based on two pieces of evidence. First, agreeing with 'Abū Albarkāt Al'Anbārī (1982:128-129), the exclamative construction does not mean that the referent has the quality exclaimed about due to the influence of 'something,' that is, the referent and the quality ascribed to it are not involved in a cause-effect relationship. In support of this argument, consider the ExclP in (52) and notice the implausibility of the second glossing for the intended meaning:

$\begin{array}{lll}\text { 52) } m \bar{a} & \text { 'a 'dama } & \text { Allah-a } \\ \text { i. PTCL } & \text { great. EXCL } & \text { Allah-ACC } \\ \text { ii. something } & \text { cause to be great } & \text { Allah- ACC } \\ \text { 'How great Allah is!' } & \end{array}$

The intended meaning indicates the high degree of Allah's greatness not that something caused Allah to be great; that is, by no means, the exclamative can be analyzed as a CAUSE-BECOME-structure in a usual TP. The second piece of evidence is related to the use of a copula kāna 'was' which demonstrates two peculiarities. First, only one auxiliary kāna 'was' can be used for semantic effect (i.e., emphasis) with no syntactic consequences (i.e., it is deprived of its case features available in clauses), other auxiliaries related to present or future cannot be utilized. Second, kāna cannot occupy its canonical position sentence initially, instead it follows the particle $m \bar{a}$ (see, e.g., Ya'īsh, 2001:423424). The non-canonical position of kāna indicates that $m \bar{a}$ in these Excls is not a noun; rather, a particle introduced into the derivation for syntactic rather than semantic reasons.

Generally speaking, the claimed analysis of the templatic V-ExclPs in (46a-c) accounts for the different case endings on the referent Zayd, viz., nominative, genitive, and accusative, respectively, although the semantics of the given constructions is consistent. This phenomenon, as well as the presence of the spurious preposition $b i$ - and the particle $m \bar{a}$, cannot be accounted for in the light of previous arguments in the literature that Excls are sentential. Moreover, the claimed superiority of this approach over clausal ones may be supported by the existence of similar structures in other languages, as argued in the following section. 


\section{Implications}

The assumptions argued so far that Arabic Excls are nonsententials imply some empirical and theoretical consequences on Excls across languages. Let us first see how the given approach provides the minimalist amount of structure to account for some peculiarities in English Excls which, as highlighted in section (2.1), include (i) the absence of S-V inversion *How smart is he!, (ii) the obligatorily movement of wh-phrase (cf. He can speak -three languages./ -what languages?/ -*what languages!), and (iii) the impossibility of preposition stranding (In a beautiful house they lived./ In which house do they live?/ vs. *In what a house they live!).

The absence of S-V inversion stems from the assumption that Excls are derived by syntactic operations affecting RPs, rather than TPs. How smart he is! can be represented as follows:

53)

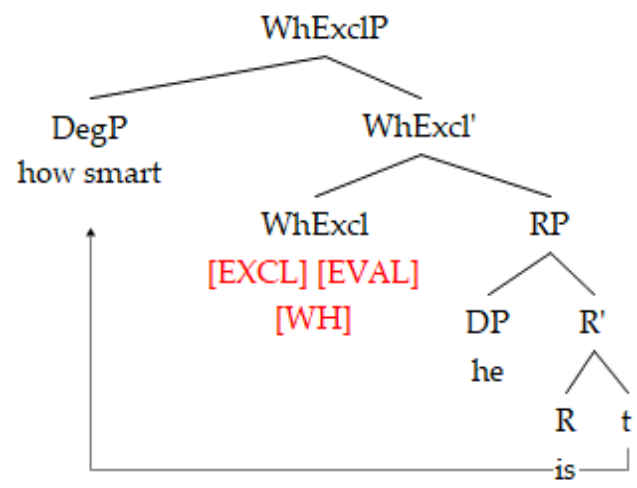

As explained in section (4), the structure of RP is asymmetrical and nondirectional in the sense that either the subject or the predicate can occupy spec-RP. In this representation, the referent he occupies the spec-RP followed by $\mathrm{R}$ which is lexicalized as the copula is, and the DegP how smart moves to spec-WhExclP for the same reasons argued for Arabic Wh-ExclPs. This simple derivation explains the absence of S-V inversion and accounts for all English Excls initiated by how which may look like full clauses although they are not.

The second peculiarity is related to the obligatory movement of wh-phrase in Excls but not in echo questions (cf. *He can speak what languages! vs., He can speak what languages?). This peculiarity can be clarified simply by assuming that what languages in the given constructions do not have the same status, that is, whereas in echo questions the wh-phrase forms one constituent which can either move or stay in situ, the same phrase in Excls is formed of two elements: the wh-word what and the DP languages that belongs to he can speak to form the DP languages he speaks, as explained in the following derivation (the internal structure of the relative clause in the DP is overlooked for ease of exposition): 


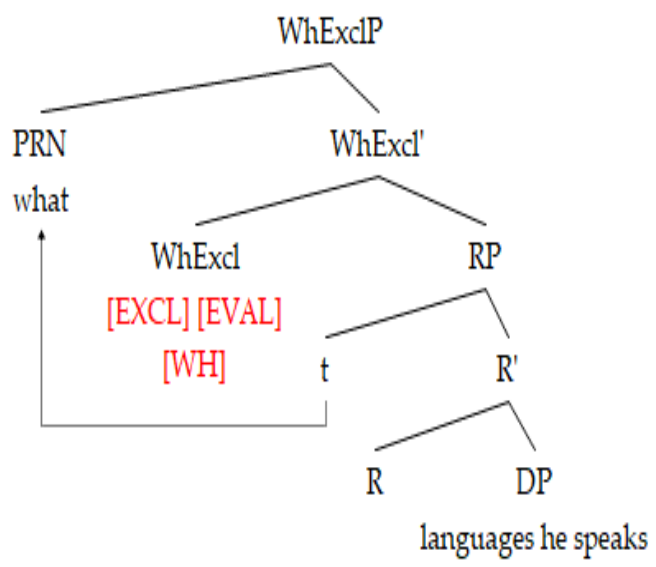

The same assumptions account for other what-Excls such as What stories she tells! which are composed of the exclamative pronoun what and the DP stories she tells. Further evidence for this assumption can be drawn from the ellipsis process which may affect only what and the result is the well-formed DP The stories she tells! but not the whole wh-phrase what stories as that leads to ungrammaticality of * She tells!.

This analysis also accounts for the mysterious requirement to strand the preposition in What a house they live in! (cf. In which house do they live? vs. *In what a house they live!). To explain, this exclamative starts the derivation as an RP formed from the referent [DP a house they live in] and an exclamative expression [AP amazing] which is due to its [EXCL] and [EVAL] features is spelled out as the exclamative pronoun what. Then, what moves to spec-WhExclP, as follows:

55)

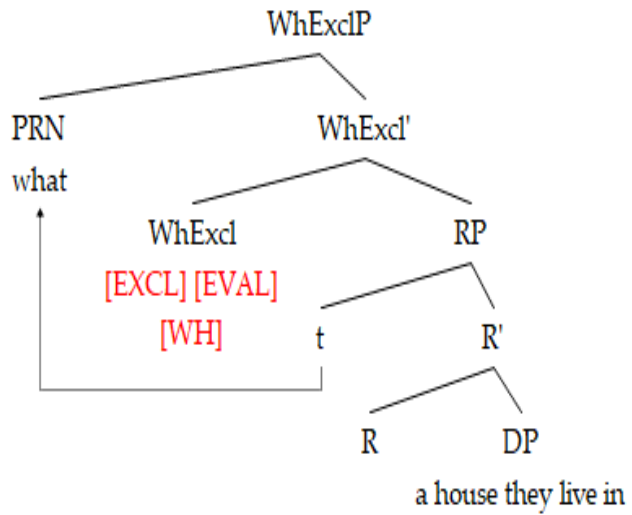

Because the exclamative is not a TP like the interrogative in which either the DP which house or the whole PP in which house moves to spec-CP, only the PRN what moves to spec-WhExclP, in cannot be pied-piped along with the wh-phrase because it exists in a separate constituent (i.e., the DP a house that they live in).

If this line of analysis is on the right track, it may have some theoretical implications not only on the derivation of Wh-ExclPs but also on formulaic questions such as those below:

56) a. What about the house?

b. How about joining us?

c. How come you missed the bus?

(Quirk \& Greenbaum, 1973:204)

In all these formulaic expressions, we notice that (i) they cannot be projected into full CPs without a change of meaning (cf. (56c) vs. How did you miss the bus?), (ii) there is an obligatory movement of 
a wh-element although no subject-verb inversion or do-support is required (cf. *you missed the bus how come?), (iii) all these formulae are directed to the addressee to 'evaluate' specific entities in (56a) or events in $(56 \mathrm{~b}, \mathrm{c})$. These properties seem similar to that of Excls to some extent, except that the exclamative pronoun is a complex form consisting of a $w h$-word with a prepositional (e.g., how about) or with a verbal form (e.g., how come) to indicate a combination of interrogation and exclamation simultaneously (i.e., two distinct communicative functions) ${ }^{25}$, and for that reason, (56a) may have the representation in (57):

57)

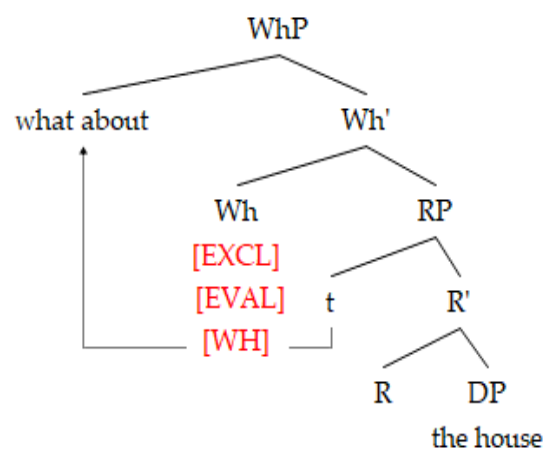

This derivation directs us to an important point related to the constituency of expressions like how beautiful in How beautiful she is!. Contra previous studies which analyze how AP as a single constituent (e.g., a QP in, e.g., Radford, 2009 and references therein), I claim that $w h$-phrases in Excls do not always form a single constituent, that is, their constituency varies across languages and language internally based on three pieces of evidence. First, since how AP cannot stay in situ (e.g., *she is how beautiful!), there is no evidence that how AP form one phrase before movement (at least in languages like Arabic and English). This argument becomes more evident when we consider whatphrases in an Excl like What a nice person he is! The what-phrase cannot be a single constituent in declaratives (*He is what a nice person.) or interrogatives (*What a nice person is he?). Secondly, crosslinguistic data shows that it is not always the case that the AP must be preceded by a degree element realized as ' $h o w$ '. Consider (58a-c) and notice that the AP can be preceded by a verb or a determiner in Spanish (58a,b) (for examples of Det-Excls in Catalan, see Miró, 2006:3), or an adverb that "cannot easily modify adjectives or adverbs in declarative clauses" (Jónsson, 2010:45) in Icelandic (58c).

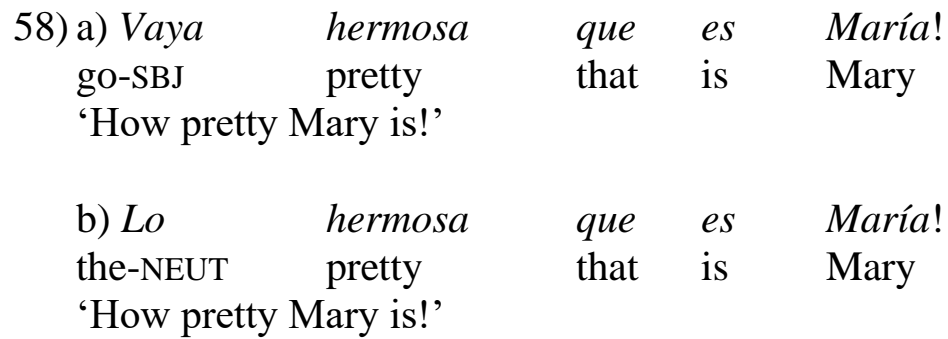

(Gutiérrez-Rexach, 2001:169)

\footnotetext{
${ }^{25}$ The complexity of the given $w h$-phrases led linguists to overlook them or to claim that they have no internal syntax, that is, "no identifiable word-class/syntactic function for the wh-phrase itself [because] it is extremely difficult, not to say impossible to judge whether these items actually do have a $w h$-feature or a syntactic function [therefore, they cannot be integrated] into the analysis of the more general properties of wh-clauses" (Trotta, 2000:35). However, in support of the claimed representation of these $w h$-phrase above, we highlight that they are "among the last acquired $w h$-questions" (Peng, 1999:25).
} 
$\begin{array}{lllll}\text { c) Mikið sto'ð } & \text { markmaðurinn } & \text { sig } & \text { vel! } \\ \text { much } & \text { did the.goal.keeper } & \text { himself } & \text { well } \\ \text { 'What a performance by the goalkeeper!' } & & \end{array}$

(Jónsson, 2010:45)

Thirdly, 'how' does not necessarily form a single constituent with the element(s) it associates with, that is, the two constituents can optionally be separated as in Mandarin Chinese (59a) or obligatorily as in French (59b) or Icelandic (59c) compared with (59d):

59) a. Tā zěnme măi nàme duō shū $a$ !

S/he how buy that.ME many book SFP

'How many books s/he bought!'

(Badan \& Cheng, 2015:388)

b. Comme elle est grande!

how she is tall

'How she's tall!'

(Zanuttini \& Portner, 2000:131)

c. Hvað pessi mynd er falleg!

how this picture is beautiful

'How beautiful this picture is!'

d. *Hvað falleg pessi mynd er!

how beautiful this picture is

(Jónsson, 2010:43)

Also, the given approach has theoretical consequences on the analysis of Voc-ExclPs in other languages such as English Oh for the rain to continue or Oh to be free! In such expressions, the adopted representation accounts for the c-command position of the vocative particle oh (cf. *For the rain to continue oh!) and the absence of an AP like desirable (cf. *Oh for the rain to continue desirable). Considering the English Oh for the rain to continue to be a $\mathrm{CP}$ derived from the TP For the rain to continue is desirable/ a great blessing wrongly predicts that $*$ Oh desirable/ a great blessing for the rain to continue is! to be grammatical (assuming a movement of AP or DP to spec$\mathrm{CP}$ with oh either originating within the moved constituent or internally merging in spec-CP). A more plausible analysis is represented in (60) where the free relative for the rain to continue originates as one constituent in RP due to its function as a DP:

60)

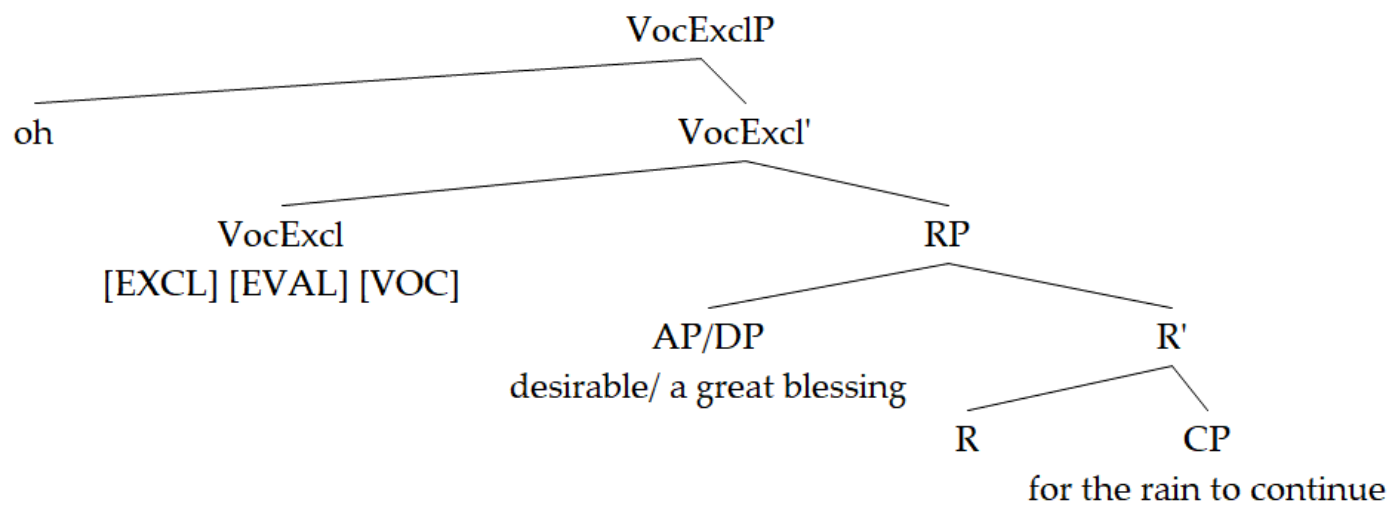

The VocExcl serves as a probe and agrees with the goal AP/DP desirable/ a great blessing. In consequence of Agreement, the values of the [EVAL] and [EXCL] features of AP/DP are copied onto VocExcl, and the [EPP] feature is satisfied by external merge of $o h$ rather than movement of the AP because Voc-Excl carries the feature [VOC] that requires the specifier of Voc-ExclP to be a vocative 
particle. The AP/DP gets null spellout by the haplology rule, as explained for Arabic Voc-ExclPs. The only difference between this representation and that of the Arabic is that the latter allows the optional preposition $l a$ - (which has the obligatory variant ' $a$ - in JA). The presence of a spurious preposition in some Arabic Excls (i.e., Voc-ExclPs and templatic V-ExclPs) is also found in other languages. Consider, for example, the Spanish preposition de 'of' which becomes obligatory in contemporary Spanish in (61a) (see, Miró, 2008:79, for Catalan de); the preposition za 'for' in Russian which does not assign case and cannot be used in cases that requires a preposition (61b); and the preposition $a$ and its variants in Mandarin Chinese which occur in structures distinct from declaratives and interrogatives in (61c) (see also the prepositions ' $i$ and $k i$ in some Oceanic languages, reported by Moyse-Faurie, 2011) ${ }^{26}$ :

$\begin{array}{llllll}\text { 61) a. Lo } & \text { que } & \text { son los niños de altos! } \\ \text { the-NEUT that are the boys of tall }\end{array}$
'How tall the boys are!'

(Gutiérrez-Rexach, 2008:124)
b. $\check{C}$ to za šutki!
what for jokes.NOM
'What [bad] jokes!'

$\begin{array}{ll}\text { c. } d u \bar{o} \text { nànkàn } & (\text { na }) ! \\ \text { how ugly } & \text { PREP } \\ \text { 'how ugly!' } & \end{array}$

(Vishenkova \& Zevakhina, 2019:13)

(Han, 1988:50)

The presence of these spurious prepositions in Arabic and other languages can be claimed to be the realization of $\mathrm{R}$.

In addition to similar phenomena of Wh-ExclPs and Voc-ExclPs, we also find similar patterns concerning V-ExclPs. Consider the Spanish V-ExclP in (62):

$\begin{array}{lll}\text { 62) Vaya hermosa que es Maria! } \\ \text { go-SBJ pretty } & \text { that is Mary }\end{array}$

'How pretty Mary is!'

(Gutiérrez-Rexach, 2001:169)

The analysis of this structure as a CP fails to account for several issues such as the placement of a verb before the adjective, the possibility of vaya, but not other verbs, in this position, and the irrelevance of the semantics of vaya and hermosa to form one constituent with the result of a combination that cannot take place in clauses. The claimed approach may provide a straightforward analysis of the Spanish V-ExclP by claiming that the AP hermosa occupies the spec-RP and vaya is base-generated in spec-VExclP to satisfy the [V] feature on VExcl. This argument may find further support in other constructions where vaya c-commands a DP, rather than an AP like hermosa. For example, vaya can extract a noun when the complementizer is que 'that', and no extraction is allowed when the complementizer is $s i$ 'if', as shown in $(63 a, b)$.

$\begin{array}{lll}\text { 63) a. Vaya libros que has } & \text { leido } \\ \text { go- SBJ books that have-you } & \text { read } \\ \text { 'The (kind of) books you have read!' } & \end{array}$

'The (kind of) books you have read!'

(Gutiérrez-Rexach, 2001:177)

\footnotetext{
${ }^{26}$ The preposition of in English ExclPs such as of all the impudence! and of all the stupid things to say! (from Ding, 2011:45) seems to me a spurious one (i.e., not semantically required). However, I haven't included it as a supportive example because of-ExclPs need further consideration which I leave for the future.
} 

b. *Vaya
idiota si
eres/
seras
go- SBJ
idiot if
are-you/
will-be-you

(Gutiérrez-Rexach, 2001:180)

This peculiarity shows that we are not dealing with extraction from a $\mathrm{CP}$, and it is not merely a lexicalization issue; in the given approach, (63a) is grammatical because the referent [libros que has leido] 'books that you have read' forms a DP, but (63b) is ill-formed because the referent [*idiota si eres] '*idiot if you are' is not a DP. Moreover, except for some idiomatic expressions, such as (64a), "raising of expressions modified by intensive determiners or headed by the preposition de is not possible with lexicalized gradable nouns" (Gutiérrez-Rexach, 2001:177), as in (64b,c), which, in my view, is related to the use of vaya as an intensive exclamative element; that is, the DP [cara que tienes] can be preceded by one intensive element vaya but not two vaya and mucha, and it cannot be a PP because it must have a DP (a referent). Due to space, other properties that may support the tenseless approach are not discussed here (see, Gutiérrez-Rexach, 2001, for more details).

$\begin{aligned} & \text { 64) a. Vaya cara que tienes! } \\ & \text { go-SUBJ face that have-you } \\ & \text { 'You have a lot of nerve!' }\end{aligned}$
$\begin{aligned} & \text { b. *Vaya mucha cara que tienes! } \\ & \text { go-SUBJ } \\ & \text { much face that have-you }\end{aligned}$
$\begin{aligned} & \text { c. *Vaya de cara que tienes! } \\ & \text { go-SUBJ }\end{aligned}$ of face that have-you

Further support can be drawn from a language like Persian in which wh-words stay in their normal position except when they are topicalized or scrambled (Sadat-Tehrani, 2011:118), as shown in (65a,b), but in Wh-Excls, the same wh-word must occupy an initial position in both what DP and how AP (66a,b), respectively (Parisa Tarahomi, p.c.):

$\begin{array}{clllll}\text { 65) a. baéče-ha } & \text { aez } & \text { un } & \text { moeqaze } & \text { ketab } & \text { xar-id-aen. } \\ \text { child-PL } & \text { from } & \text { that } & \text { shop } & \text { book } & \text { buy-PST-3PL }\end{array}$

'The children bought books from that shop.'

$\begin{array}{llllll}\text { b. boěče-ha } & a e z & \text { un } & \text { maqaze } & \check{c} i & \text { xar-id-cen? } \\ \text { child-PL } & \text { from } & \text { that } & \text { shop } & \text { what } & \text { buy-PST-3PL }\end{array}$

'What did the children buy from that shop?'

66) a. kuh bozorg ast./?

mountain big is

'The mountain is big. / Is the mountain big?'

b. $\check{c} i \quad k u h-i$

what mountain-INDEF

'What a mountain!'
b. $\check{c} i \quad k u h-i$
bozorg-i
what mountain-INDEF
big-INDEF

'How big the mountain is!' 
What is also interesting in Persian is that the other exclamative element, viz., 'ajab, can be used interchangeably with $\check{c} i$ ' what', but it cannot be used in interrogatives. This fact may indicate that ExclPs are syntactically distinct from full sentences in Persian. Needless to say, such claims are just preliminary predictions that need to be argued for or against by other cross-linguistic studies in the future.

\section{Summary and conclusion}

This paper provides a general overview and a critical assessment of the essential characteristics of Excls, and it examines and analyzes the morphosyntactic structure of Excls in Arabic. An overview of previous studies shows that the syntactic strategies utilized in Excls are related to phrasal, rather than clausal, structures (i.e., wh-phrases, subordinate clauses, and noun phrases), and that debatable issues involve the basic characteristics of Excls, viz., clausal type, defining features, and their analyses. Concerning their clause type, the paper argues that Excls are unambiguously distinguishable from clauses since they have unique syntactic structures (i.e., non-TPs) and definable semantic and pragmatic properties. The defining features argued in the literature (i.e., factivity, scalar implicature, and question/answer relations) are shown to be highly controversial and cross-linguistically invalid, the paper suggests that evaluation and referentiality features are more plausible and also essential to account for the syntax of Excls since they are associated with the main components of exclamative phrases, namely, the subject (i.e., the referent) and the property ascribed to it (i.e., the exclamative expression). Regarding previous clausal analyses, the paper claims that assuming Excls to be TPs led to two unsatisfactory consequences, viz., inconsistency (i.e., each study claims several projections in the $\mathrm{C}$ domain which are different from those in other studies in their number, categories, functional heads and features) and complication (i.e., unavoidable complicated derivations with multiple projections are required to differentiate between Excls and non-Excls).

Based on the claimed inadequacies of previous clausal analyses, the paper adopts a more straightforward approach that assumes Excls to be non-TP constructions which start the derivation as asymmetrical and nondirectional RP selected by Excl which carries the unvalued [EVAL] and [EXCL] features which are valued by the AP and the [EPP] feature which requires the spec-ExclP to be lexically realized. Depending on the type of ExclP, Excl also carries [WH] in Wh-ExclPs, [VOC] in Voc-ExclPs, and [V] in V-ExclPs. This approach is argued to account for the peculiarities and intricacies associated with the different types of Arabic ExclPs such as (i) their inflexible word order, (ii) case alternation on the referent in templatic V-ExclPs, (iii) the presence of spurious prepositions obligatorily (e.g., $b i$ - in imperative templatic V-ExclPs) or optionally (e.g., la- in Voc-ExclPs), and (vi) the obligatory presence of some meaningless elements (e.g., the demonstrative-like ha- in WhExclPs and the particle $m \bar{a}$ in V-ExclPs).

The analysis of Wh-ExclPs shows that the different distributions of the two wh-elements $̌ \bar{s}$ and ayš supports the phrasal nature of this type. The given approach explains the intricacies associated with the inflexible word order, the obligatory presence of $h a$-preceding the DP, and the different selectional properties of the $\breve{s} \bar{u}$-/ ayš-forms. Moreover, the given arguments are claimed to imply theoretical consequences on English $w h$-Excls and formulaic questions and to provide a more satisfactory account of their idiosyncrasies based on supportive data from Spanish, Icelandic, Mandarin Chinese, and French.

The paper shows that VocPs are distinguished from Voc-ExclPs based on a number of syntactic properties (i.e., case assignment and selectional requirements) and semantic features (i.e., [REFEREnTiality], [EVAluative], [Animacy] and [DEGREe]). Also, the analysis of Voc-ExclPs 
clarifies the syntactic motivations behind the absence of a predicative AP and the presence of semantically empty prepositions. The vocative particle $y \bar{a}$ 'oh' is argued to have the same syntactic features of the AP, and by syntactic haplology, the AP gets a null spell-out. The spurious prepositions $l a$ - and ' $a$ - are argued to be the lexical realizations of R. Such prepositions are attested by crosslinguistic data (e.g., Spanish de, Russian za, Mandarin Chinese $a$, and ' $i$ and $k i$ in some Oceanic languages). Additionally, the paper explores the two strategies involved in V-ExclPs (i.e., evaluative verb and morphological templates). The argued approach provides a straightforward analysis and explanation for evaluative verbs, especially, their nominal and verbal properties, obligatory initial position, and existence only at the non-clausal level. Moreover, it clarifies the debatable categorial status of exclamative templates, their case assignment properties, and the presence of the spurious preposition $b i$ - and the particle $m \bar{a}$.

\section{References}

Abels, K. (2010). Factivity in Exclamatives Is a Presupposition. Studia Linguistica: A Journal of General Linguistics, 64(1), 141-157.

Adger, D., \& Ramchand, G. (2003). Predication and equation. Linguistic Inquiry, 34(3), 325-359.

Al-Ansari, I. H. (1991). Mughni Al-Labib (M. Abd Al-Hamid, Ed.). Al Asriyyah Library. https://www.alkitab.com/50065.html

Al-Aqarbeh, R. N. (2011). Finiteness in Jordanian Arabic: A semantic and morphosyntactic approach. University of Kansas.

Al-Bataineh, H. (2019). Emphasis Harmony in Arabic: A Critical Assessment of Feature-Geometric and Optimality-Theoretic Approaches. 79. https://doi.org/10.3390/languages4040079

Al-Bataineh, H. (2020). The syntax of Arabic vocatives. Brill's Journal of Afroasiatic Languages and Linguistics, 1(aop), 1-33. https://doi.org/10.1163/18776930-01202100

Al-Bataineh, H., \& Branigan, P. (2020). The syntax of (complex) numerals in Arabic [Unpublished manuscript]. https://doi.org/10.31219/osf.io/6pesa

Alhawary, M. T. (2011). Modern Standard Arabic Grammar: A Learner's Guide. John Wiley \& Sons, Incorporated.

Alkuwaihes, G. (2017). The Derivation of Vocative Exclamatives with the Particle Paya in Gulf Arabic. International Journal of Language and Linguistics, 5(5), 121.

Almasā̄î̀, N., \& Almalḳ, H. (2015). 'Ațr Al'alāma Allugiauyya fī Annaḥū Al'arbī . Majalat Almanārah Lilbuḥūt Waddirāsāt, $\quad 21(3), \quad$ 1-22. https://repository.aabu.edu.jo/jspui/handle/123456789/1268

Alqurašī, A. S., \& Almusawī, M. M. (2010). Șayg̉ Atta 'jb Assamā'ya. Wasiṭ Lal 'lūm Al'insānya, 13, 9-44. 
Al-Shawashreh, E. (2016). Aspects of grammatical variation in Jordanian Arabic. Université d'Ottawa/University of Ottawa.

Al'Anbārī, 'Abū Albarkāt. (1982). Al'Inșāffì Masā ìl Alḳilāf bayn Annaḥwyīn Albaṣrȳ̄n wa Lkawfȳ̄n (M. 'Abd Alḥamīd, Ed.). Almaktba Al'așrya.

Ambar, M. (2002). Wh-Questions and Wh-Exclamatives Unifying Mirror Effects. In C. Beyssade, R. Bok-Bennema, F. Drijkoningen, \& P. Monachesi (Eds.), Romance Languages and Linguistic Theory 2000: Selected Papers from "Going Romance" 2000, Utrecht, 30 November-2 December (pp. 15-40). John Benjamins Publishing.

Apresjan, J. D. (1977). Concerning One Rule in the Amalgamation of Lexical Meanings. Linguistics, 15(185), 5-26.

Aqeel, I. (1980). Sharh Ibn Aqeel of the Alfiyyah of Ibn Malik (20th ed.). Dar Masir.

Badan, L., \& Cheng, L. L.-S. (2015). Exclamatives in Mandarin Chinese. Journal of East Asian Linguistics, 24(4), 383-413. https://doi.org/10.1007/s10831-015-9136-Z

Bailyn, J. F. (1995). A configurational approach to Russian" free" world order [Ph.D. Dissertation]. Cornell University.

Bailyn, J. F., \& Citko, B. (1999). Case and agreement in Slavic predicates. Formal Approaches to Slavic Linguistics, 7, 17-37.

Bailyn, J. F., \& Rubin, E. J. (1991). The unification of instrumental case assignment in Russian. Cornell Working Papers in Linguistics, 9(1), 99-126.

Baker, M. C. (2003). Lexical Categories: Verbs, Nouns and Adjectives. Cambridge University Press.

Bakir, M. J. (2019). A focus operator in Iraqi Arabic. In A. Khalfaoui \& M. A. Tucker (Eds.), Perspectives on Arabic Linguistics XXX: Papers from the annual symposia on Arabic Linguistics, Stony Brook, New York, 2016 and Norman, Oklahoma, 2017 (Vol. 7, pp. 113132). John Benjamins Publishing Company.

Basilico, D. (2003). The topic of small clauses. Linguistic Inquiry, 34(1), 1-35.

Benmamoun, E., Abunasser, M., Al-Sabbagh, R., Bidaoui, A., \& Shalash, D. (2013). The Location of Sentential Negation in Arabic Varieties. Brill's Journal of Afroasiatic Languages and Linguistics, 5(1), 83-116. https://doi.org/10.1163/18776930-00501003

Bennis, H., Corver, N., \& den Dikken, M. (1998). Predication in nominal phrases. The Journal of Comparative Germanic Linguistics, 1(2), 85-117.

Bittner, M. (2005). Future discourse in a tenseless language. Journal of Semantics, 22(4), 339-387.

Bittner, M. (2008). Aspectual universals of temporal anaphora. In S. Rothstein (Ed.), Theoretical and crosslinguistic approaches to the semantics of aspect (Vol. 11, pp. 349-385). John Benjamins.

Bohnemeyer, J. (2002). The grammar of time reference in Yukatek Maya. Lincom Europa. 
Bohnemeyer, J. (2009). Temporal anaphora in a tenseless language. In W. Klein \& P. Li (Eds.), The expression of time in language (pp. 83-128). Mouton de Gruyter.

Bohnemeyer, J., \& Swift, M. (2004). Event realization and default aspect. Linguistics and Philosophy, 27(3), 263-296.

Borik, O., \& Espinal, M.-T. (2019). Definiteness in Russian bare nominal kinds. In A. AguilarGuevara, J. P. Loyo, \& V. V.-R. Maldonado (Eds.), Definiteness across languages (pp. 293318). Language Science Press.

Bowers, J. (1993). The syntax of predication. Linguistic Inquiry, 24(4), 591-656.

Brandner, E. (2010). On the Syntax of Verb-Initial Exclamatives. Studia Linguistica: A Journal of General Linguistics, 64(1), 81-115.

Bresnan, J. (1997). Mixed categories as head sharing constructions. Proceedings of the LFG97 Conference, Stanford: On Line CSLI Publ.

Cantarino, V. (1976). Syntax of Modern Arabic Prose: The Expanded Sentence v. 2 (International Development Research Center. Studies in development, no. 5) (Vol. 2). Indiana University Press.

Castroviejo, E. (2019). On wh-exclamatives and gradeability. An argument from Romance. Journal of Linguistics, 1-42. https://doi.org/10.1017/S0022226719000306

Chomsky, N. (2001). Derivation by phase. In M. Kenstowicz (Ed.), Ken Hale: A life in language (pp. 1-52). Mit Press.

Chomsky, N. (2008). On phases. In R. Freidin, C. Otero, \& M. L. Zubizarreta (Eds.), Foundational Issues in Linguistic Theory: Essays in Honor of Jean-Roger Vergnaud (pp. 133-167). MIT Press.

Chomsky, N. (2015). Problems of projection. In E. Di Domenico, C. Hamann, \& S. Matteini (Eds.), Structures, strategies and beyond: Studies in honour of Adriana Belletti (Vol. 223). John Benjamins Publishing Company.

Citko, B. (2006). Copula sentences reconsidered. In J. E. Lavine, S. Franks, M. Tasseva-Kurktchieva, \& H. Filip (Eds.), Annual Workshop on Formal Approaches to Slavic Linguistics 14: The Princeton Meeting 2005 (pp. 83-98). Michigan Slavic Publications.

Citko, B. (2008). Small clauses reconsidered: Not so small and not all alike. Lingua, 118(3), 261295. https://doi.org/10.1016/j.lingua.2007.05.009

Citko, B. (2011). Small Clauses. Language and Linguistics Compass, 5(10), 748-763. https://doi.org/10.1111/j.1749-818X.2011.00312.x

Corver, N. (2008). Uniformity and diversity in the syntax of evaluative vocatives. The Journal of Comparative Germanic Linguistics, 11(1), 43. https://doi.org/10.1007/s10828-008-9017-1

Cruschina, S., Giurgea, I., \& Remberger, E.-M. (2015). Focus fronting between declaratives and exclamatives. Revue Roumaine de Linguistique, 60, 257-275. 
Daniel, M., \& Spencer, A. (2009). The Vocative - An Outlier Case. In A. Malchukov \& A. Spencer (Eds.), The Oxford Handbook of Case (pp. 626-634). Oxford University Press.

D’Avis, F. (2016). Different Languages - Different Sentence Types? On Exclamative Sentences. Language and Linguistics Compass, 10(4), 159-175. https://doi.org/10.1111//nc3.12181

Delsing, L.-O. (2010). Exclamatives in Scandinavian. Studia Linguistica, 64(1), 16-36.

den Dikken, M. (2006). Relators and Linkers The Syntax of Predication, Predicate Inversion, and Copulas (Vol. 47). MIT Press.

Ding, Y. (2011). Implied Negation in Discourse. Journal of Theory and Practice in Language Studies, 1(1), 44-51.

Dragacevic, S. (2002). Time computation in tenseless languages. [Ph.D. Dissertation, SOAS University of London].

Elliott, D. E. (1974). Toward a Grammar of Exclamations. Foundations of Language, 11(2), 231246.

El-Yasin, M. K. (1985). Basic word order in classical Arabic and Jordanian Arabic. Lingua, 65(1-2), $107-122$.

Endo, Y., \& Haegeman, L. (2019). Adverbial clauses and adverbial concord. Glossa: A Journal of General Linguistics, 4(1).

Fassi Fehri, A. (1993). Issues in the Structure of Arabic Clauses and Words. Springer Science \& Business Media.

Faust, N. (2018). Exponence, allomorphy and haplology in the number and State morphology of Modern Hebrew. Glossa: A Journal of General Linguistics, 3(1).

Firanescu, D. R. (2003). Exclamation in modern literary Arabic. A pragmatic perspective [Ph.D. Dissertation]. Editura Universitari din Buca.

Grimshaw, J. (1979). Complement Selection and the Lexicon. Linguistic Inquiry, 10(2), 279-326. JSTOR.

Gutiérrez-Rexach, J. (2001). Spanish exclamatives and the interpretation of the left periphery. In Y. D’hulst, J. Rooryck, \& J. Schroten (Eds.), Romance Languages and Linguistic Theory 1999: Selected papers from “Going Romance” 1999, Leiden, 9-11 December 1999 (pp. 167-194). John Benjamins Publishing.

Gutiérrez-Rexach, J. (2008). Spanish Root Exclamatives at the Syntax/Semantics Interface. Catalan Journal of Linguistics, 7(1), 117-133. https://doi.org/10.5565/rev/catjl.134

Han, Y. (1988). A pragmatic study of some sentence-final and post-verbal particles in Mandarin Chinese. University of York.

Hiraiwa, K. (2010). The syntactic OCP. The Proceedings of the 11th Tokyo Conference on Psycholinguistics, 35-56. 
Honda, M. (2011). Wh-exclamatives, factivity, and topicalization revisited. Studies in Language Sciences, 17, 87-117. https://ci.nii.ac.jp/naid/110008439970/

Hornstein, N., \& Lightfoot, D. (1987). Predication and PRO. Language, 23-52.

Ibn Ya'īsh, M.-A. (2001). Sharh Al-mufaSSal Lil-Zamaxsharī ('Imīl Ya'qūb, Ed.; 1st ed., Vol. 4). Dar Al-Kotob Al-ilmyah.

Jónsson, J. G. (2010). Icelandic Exclamatives and the Structure of the CP Layer. Studia Linguistica: A Journal of General Linguistics, 64(1), 37-54.

Kiparsky, P., \& Kiparsky, C. (1970). Fact. In M. Bierwisch \& K. E. Heidolph (Eds.), Progress in linguistics: A collection of papers (Vol. 43, pp. 143-173). Walter de Gruyter.

Lambrecht, K. (1996). Information structure and sentence form: Topic, focus, and the mental representations of discourse referents (Vol. 71). Cambridge university press.

Lasnik, H. (1990). Restricting the theory of transformations: A case study. In Essays on restrictiveness and learnability (pp. 125-145). Springer.

Lasnik, H. (1995). Verbal morphology: Syntactic structures meets the Minimalist Program. Evolution and Revolution in Linguistic Theory: Studies in Honor of Carlos P. Otero, 251-275.

Lin, J. (2010). A Tenseless Analysis of Mandarin Chinese Revisited: A Response to Sybesma 2007. Linguistic Inquiry, 41(2), 305-329. https://doi.org/10.1162/ling.2010.41.2.305

Lin, J.-W. (2006). Time in a Language Without Tense: The Case of Chinese. Journal of Semantics, 23(1), 1-53. https://doi.org/10.1093/jos/ffh033

Markman, V. (2008). Pronominal copula constructions are what? Reduced specificational pseudoclefts. Proceedings of the 26th West Coast Conference on Formal Linguistics, 366-374.

Michaelis, L. (2001). Exclamative constructions. In M. Haspelmath, E. König, W. Oesterreicher, \& W. Raible (Eds.), Language typology and language universals: An international handbook (Vol. 20, pp. 1038-1049). Walter de Gruyter.

Miró, E. C. (2006). “Wh”-exclamatives in Catalan [Ph.D. Dissertation, Universitat de Barcelona].

Miró, E. C. (2008). Deconstructing Exclamations. Catalan Journal of Linguistics, 7, 41-90-90.

Mohammed, A.-S. M. (2018). The problem of some multi-functions of the Arabic particles (مَنْ) 'Men'and (مَان)'Maa'with reference to translation. Journal Of Al-Frahedis Arts, 1(34), 2537.

Moutaouakil, A. (2005). Exclamation: Sentence type, illocution or modality? In C. de Groot \& K. Hengeveld (Eds.), Morphosyntactic expression in functional grammar (pp. 351-379). Mouton de Gruyter.

Moyse-Faurie, C. (2011). Nominalization and exclamation in Oceanic languages. Topics in Oceanic Morphosyntax, 111-136. 
Neeleman, A., \& Van de Koot, H. (2006). Syntactic haplology. The Blackwell Companion to Syntax, 685-710.

Nouwen, R., \& Chernilovskaya, A. (2013). Wh-exclamatives with and without scales. Ms. Available from: Http://Ricknouwen. Org/Rwfn/Papers/. Last Accessed, 15, 2013.

Obenauer, H.-G. (1994). Aspects de la syntaxe A-barre: Effets d'intervention et mouvements des quantifieurs. Paris 8.

Oda, T. (2008). Degree constructions in Japanese. University of Connecticut.

O'Neill, T. (2015). The domain of Finiteness: Anchoring without Tense in copular amalgam sentences: The Graduate Center [Ph.D. Dissertation]. The City University of New York.

Ono, H. (2006). An investigation of exclamatives in English and Japanese: Syntax and sentence processing [Ph.D. Dissertation]. University of Maryland.

Oomen, U. (1979). Structural Properties of English Exclamatory Sentences. Folia Linguistica: Acta Societatis Linguisticae Europaeae, 13(1/2), 159-174.

Peng, L. L. (1999). Acquisition of Wh-questions by a Cantonese-English Bilingual Child. The Chinese University of Hong Kong.

Potsdam, E. (2011). Expressing exclamatives in Malagasy. Nominalizations in Asian Languages: Diachronic and Typological Perspectives, 659-683.

Potts, C., \& Roeper, T. (2006). The narrowing acquisition path: From expressive small clauses to declaratives. In L. Progovac, K. Paesani, E. Casielles, \& E. Barton (Eds.), The Syntax of Nonsententials: Multidisciplinary perspectives (pp. 183-201). John Benjamins Publishing.

Progovac, L. (2006). The syntax of nonsententials: Small clauses and phrases at the root. In L. Progovac, K. Paesani, E. Casielles, \& E. Barton (Eds.), The Syntax of Nonsententials: Multidisciplinary perspectives (pp. 33-71). John Benjamins Publishing.

Quirk, R., \& Greenbaum, S. (1973). A University Grammar of English (Abridged edition edition). Longman.

Radford, A. (2009). Analysing English Sentences. Cambridge University Press.

Richards, M. D. (2007). On feature inheritance: An argument from the Phase Impenetrability Condition. Linguistic Inquiry, 38(3), 563-572.

Rosengren, I. (1997). Expressive Sentence Types- A Contradiction in Terms. The Case of Exclamation. In T. Swan \& O. J. Westvik (Eds.), Modality in Germanic Languages: Historical and Comparative Perspectives (pp. 151-184). Walter de Gruyter.

Ryding, K. C. (2005). A Reference Grammar of Modern Standard Arabic (1st edition). Cambridge University Press.

Sadat-Tehrani, N. (2011). The Intonation Patterns of Interrogatives in Persian. Linguistic Discovery, 9(1). 
Schumacher, P. B. (2019). Vagueness and context-sensitivity of absolute gradable adjectives. In Snippets 37. Special issue in honor of Uli Sauerland (pp. 90-93). LED.

Shlonsky, U. (1997). Clause structure and word order in Hebrew and Arabic: An essay in comparative Semitic syntax. Oxford University Press.

Siemund, P. (2015). Exclamative clauses in English and their relevance for theories of clause types. Studies in Language. International Journal Sponsored by the Foundation "Foundations of Language, " 39(3), 698-728. https://doi.org/10.1075/s1.39.3.06sie

Soltan, U. (2007). On formal feature licensing in minimalism: Aspects of Standard Arabic morphosyntax [Ph.D. Dissertation]. University of Maryland.

Svenonius, P. (1994). Dependent nexus: Subordinate predication structures in English and the Scandinavian languages [Ph.D. Dissertation]. University of California, Santa Cruz.

Trotta, J. (2000). Wh-clauses in English: Aspects of Theory and Description. Rodopi.

Villalba, X. (2008). Exclamatives: A Thematic Guide with Many Questions and Few Answers. Catalan Journal of Linguistics, 7(1), 9-40. https://doi.org/10.5565/rev/catj1.131

Vishenkova, A., \& Zevakhina, N. (2019). Wh-exclamatives with and without predicates in Russian. Russian Linguistics, 1-19. https://doi.org/10.1007/s11185-019-09213-x

Wong, S. Y., Huang, C.-R., \& Chen, I.-H. (2018). Facilitating and Blocking Conditions of Haplology: A comparative study of Hong Kong Cantonese and Taiwan Mandarin. Proceedings of the 32nd Pacific Asia Conference on Language, Information and Computation.

Woolford, E. (2003). Nominative objects and Case locality. Formal Approaches to Slavic Linguistics, $11,539-568$.

Yamato, N. (2010). The Left Periphery of Japanese Exclamatives. Studia Linguistica: A Journal of General Linguistics, 64(1), 55-80.

Zanuttini, R., \& Portner, P. (2000). The Characterization of Exclamative Clauses in Paduan. Language, 76(1), 123-132. JSTOR. https://doi.org/10.2307/417396

Zevakhina, N. (2013). Syntactic strategies of exclamatives. The Journal of Estonian and Finno-Ugric Linguistics (ESUKA - JEFUL), 4(2), 157-178. 